\title{
Review Article \\ Titanium Dioxide as a Catalyst Support in Heterogeneous Catalysis
}

\author{
Samira Bagheri, Nurhidayatullaili Muhd Julkapli, and Sharifah Bee Abd Hamid \\ Nanotechnology \& Catalysis Research Centre (NANOCAT), IPS Building, University of Malaya, 50603 Kuala Lumpur, Malaysia \\ Correspondence should be addressed to Nurhidayatullaili Muhd Julkapli; nurhidayatullaili@um.edu.my
}

Received 28 April 2014; Revised 22 July 2014; Accepted 10 August 2014; Published 14 October 2014

Academic Editor: Alexander Vorontsov

Copyright (C) 2014 Samira Bagheri et al. This is an open access article distributed under the Creative Commons Attribution License, which permits unrestricted use, distribution, and reproduction in any medium, provided the original work is properly cited.

\begin{abstract}
The lack of stability is a challenge for most heterogeneous catalysts. During operations, the agglomeration of particles may block the active sites of the catalyst, which is believed to contribute to its instability. Recently, titanium oxide $\left(\mathrm{TiO}_{2}\right)$ was introduced as an alternative support material for heterogeneous catalyst due to the effect of its high surface area stabilizing the catalysts in its mesoporous structure. $\mathrm{TiO}_{2}$ supported metal catalysts have attracted interest due to $\mathrm{TiO}_{2}$ nanoparticles high activity for various reduction and oxidation reactions at low pressures and temperatures. Furthermore, $\mathrm{TiO}_{2}$ was found to be a good metal oxide catalyst support due to the strong metal support interaction, chemical stability, and acid-base property. The aforementioned properties make heterogeneous $\mathrm{TiO}_{2}$ supported catalysts show a high potential in photocatalyst-related applications, electrodes for wet solar cells, synthesis of fine chemicals, and others. This review focuses on $\mathrm{TiO}_{2}$ as a support material for heterogeneous catalysts and its potential applications.
\end{abstract}

\section{Introduction}

1.1. Essential Principle of Catalyst. The catalysis industry is a billion-dollar industry that accounts for the manufacture of $60 \%$ of all the chemicals that are utilized for most chemical processes [1-6]. Some of the products derived from catalytic processes include polymers [2], plastics [3], pharmaceuticals [4], and detergents [5]. After decades of research, systematic information on the catalytic properties of many catalysts has been established and accumulated. From the literature, it is concluded that one of the major limitations of the catalytic reaction is separation and distribution [7-9]. Many of real catalysts are made up of small (in the nanometer range) sizes. This consequently brought about the uncertainly and nonuniformity of the materials involved, the preparation methods, and surface conditions [8]. Heterogeneous catalyst was introduced to overcome the separation and distribution problems.

1.2. Importance of Heterogeneous Catalyst. Heterogeneous catalysts have become a crucial part of many industrial activities, such as organic synthesis, oil refining, and pollution control [10-15]. Modern heterogeneous catalysts consist of several elements in precise proportions [12]. Currently, heterogeneous catalysts are optimized for the greatest reaction rate, which in turn results in optimal selectivity [1113]. It is possible to improve the heterogeneous catalyst activity over modifying the support by approaches such as nanotechnology and nanoscience or controlling the pore structure [14-16]. For heterogeneous catalysis, the problem of catalyst separation and recovery from the reaction matrix are addressed by using various catalyst supports to immobilize the particle [15]. This in turn provides a large enough surface area for the heterogeneous catalyst for it not to dissolve into the solution matrix [16]. Therefore, the heterogeneous catalyst with broad supports such as $\mathrm{Al}_{2} \mathrm{O}_{3}, \mathrm{TiO}_{2}, \mathrm{ZrO}_{2}, \mathrm{ZnO}$, and others is applied based on its broad availability and costeffective modes of synthesis.

1.3. Importance of Heterogeneous Catalyst Support. Recently, the importance of an appropriate catalyst's support material has been of huge interest. The idea is that the main catalyst should be dispersed on a suitable support to make the catalytic nanoparticles stable and obtain optimal performance 
and decrease the amount of costly metal being utilized, which accordingly decrease the total catalyst expenses [11, 15]. Furthermore, with porous characteristics, support materials offer a high dispersion of nanoparticle catalyst and simplify electron transfer, both of which contribute to better catalytic activities [17-20].

However, the heterogeneous catalyst support may sometime exert a structural effect, brought about by textural and active phase-linked effect [18]. Thus, the selection on support heterogeneous catalyst must retain its specific properties, such as porosity, surface area, dispersion, selectivity, and activity [19-21]. The morphology and pores size of the selected support materials play an important role in enhancing the heterogeneous catalyst's stability and performance [20].

According to the literature, the support of the heterogeneous catalyst can be alumina [22], zeolites [23], carbon nanofibers [19], active carbon [17], and metal oxides [13], such as $\mathrm{TiO}_{2}, \mathrm{La}_{2} \mathrm{O}_{3}, \mathrm{CeO}_{2}, \mathrm{MnO}_{2}$, and $\mathrm{ZrO}_{2} . \mathrm{TiO}_{2}$ is a recognized heterogeneous catalyst support that is broadly utilized in fuel processing due to its tunable porous surface and distribution, high thermal stability, and mechanical strength [24, 25]. Being used in this manner contributes to the ability of $\mathrm{TiO}_{2}$ to develop Lewis acidity as well as redox properties [25].

\section{2. $\mathrm{TiO}_{2}$ : In General}

$\mathrm{TiO}_{2}$ has proven to be one of the promising $n$-type semiconductors due to its wide band gap $(3.2 \mathrm{eV})$ under ultraviolet light [24]. Additionally, possessing high physical and chemical stability as well as the high refractive index makes this material widely researched [25]. Due to its electronic and optical properties, it can be utilized in several fields, such as solar cells, photocatalyst, sensors, and self-cleaning [26]. In electrochemistry, $\mathrm{TiO}_{2}$ based materials play a key role due to their high conductivity and stability in alkaline and acid media. $\mathrm{TiO}_{2}$ exists in three crystalline forms; anatase and rutile are the most common types, and the crystalline size of the rutile is always larger than the anatase phase. Brookite is the third structural form, an orthorhombic structure, which is rarely utilized, and is of no interest for most applications [27-30]. Rutile phase is the most thermally stable among the three phases. Brookite and anatase crystalline, above $600^{\circ} \mathrm{C}$, experience a phase transition and convert into the rutile phase $[28,29]$. The anatase phase contains zigzag chains of octahedral molecules linked to each other, while the rutile consists of linear chains of opposite edge-shared octahedral structure [29-32]. Generally, the anatase-to-rutile phase transformation occurs between $600-700^{\circ} \mathrm{C}$, but, for certain applications, it is required that $\mathrm{TiO}_{2}$ anatase be stable at $900^{\circ} \mathrm{C}$ [31]. Generally, the anatase $\mathrm{TiO}_{2}$ nanoparticles are stabilized by the addition of cations [32].

The synthesis techniques of $\mathrm{TiO}_{2}$ usually require high temperatures to crystallize the amorphous material into one of the phases of $\mathrm{TiO}_{2}$, such as brookite, anatase, and rutile, consequently leading to larger particles and typically nonporous materials [33-35]. Recently, low temperature synthesis methods resulted in crystalline $\mathrm{TiO}_{2}$ with a higher degree of control over the formed polymorph and its intra- or interparticle porosities [32]. There are reports on the formation of crystalline nanoscale $\mathrm{TiO}_{2}$ particle via solution based approach without thermal treatment with special focus on the resulting polymorphs, surface area, particle dimensions, and crystal morphology [34]. There are exceptional emphases on the sol-gel method via glycosylated precursor and also the miniemulsion method [30-32].

$\mathrm{TiO}_{2}$, due to its nontoxicity, long-term photo stability, and high effectiveness, has been widely utilized in mineralizing toxic and nonbiodegradable environmental contaminants. $\mathrm{TiO}_{2}$ possesses good mechanical resistance and stabilities in acidic and oxidative environments. These properties make $\mathrm{TiO}_{2}$ a prime candidate for heterogeneous catalyst support.

2.1. $\mathrm{TiO}_{2}$ : As a Heterogeneous Catalysis. It has been demonstrated that $\mathrm{TiO}_{2}$ improve the performance of catalysts [35-39], allowing the modulation of catalytic activities for many reactions, including dehydrogenation [38, 39], hydrodesulphurization [37], water gas shift [36], and thermal catalytic decomposition [35].

There are also some obvious drawbacks in using $\mathrm{TiO}_{2}$ as a heterogeneous catalysis. The limitations included small specific surface areas, low quantum efficiency, and low adsorption abilities [36, 37]. Furthermore, both costs and difficulties in the separation of catalyst from the reaction media and inadequacy for continuous processing limited the applications of $\mathrm{TiO}_{2}$ as a heterogeneous catalyst in largescale industries [38]. Despite these drawbacks, a number of studies have focused on catalytic reaction with $\mathrm{TiO}_{2}$ as a support material. The mesoporous $\mathrm{TiO}_{2}$ of pure anatase phase with sharp pore distribution and large surface area was synthesized to increase the degree of distribution and homogeneity of immobilized catalyst $[39,40]$. The influences of $\mathrm{TiO}_{2}$ support on heterogeneous catalysts affect electronic effects and bifunctional mechanism [41]. $\mathrm{TiO}_{2}$, as a catalyst support, enforces an electronic effect where the hypo-delectronic $\mathrm{Ti}^{3+}$ promotes electrocatalytic features of hyperd-electronic noble catalyst surface atoms [42]. This, in turn, decreases the adsorption energy of CO intermediates, while enhancing the mobility of $\mathrm{CO}$ groups. At the same time, the adsorption of $\mathrm{OH}$ species on $\mathrm{TiO}_{2}$ tends to facilitate the conversion of the catalytically toxic $\mathrm{CO}$ intermediates in $\mathrm{CO}_{2}$, thus improving the durability of the heterogeneous catalyst $[43,44]$. Both factors indirectly assist the dispersion and anchor of the heterogeneous catalyst particle [44]. Further improvement in the catalytic stability and activity of the heterogeneous catalysts involves modifying the $\mathrm{TiO}_{2}$ support material with semiconductor metal oxides.

\section{3. $\mathrm{TiO}_{2}$ : As Support in Heterogeneous Catalysis}

Among different material candidates such as nitrides, perovskites, and carbides, $\mathrm{TiO}_{2}$ based catalyst support materials are known to have excellent properties [44], due to $\mathrm{TiO}_{2}$ nanoparticles high chemical and thermal stability. $\mathrm{TiO}_{2}$ based catalyst supports have outstanding resistance towards corrosion in different electrolytic media. $\mathrm{TiO}_{2}$ can be regarded 
TABLE 1: List of advantages and disadvantages of heterogeneous catalysis system.

\begin{tabular}{|c|c|c|}
\hline Type of catalysis support & Advantages & Disadvantages \\
\hline Organic polymer & $\begin{array}{l}\text { (i) Easy and versatile functionalization, especially } \\
\text { for the polymer containing aryl group } \\
\text { (ii) Hydrocarbon polymers are chemically } \\
\text { inert-support does not interfere with catalytic } \\
\text { groups } \\
\text { (iii) It can be prepared with a width range of } \\
\text { physical properties (porosity, surface area, and } \\
\text { solution characteristics) }\end{array}$ & $\begin{array}{l}\text { (i) It has poor heat transfer ability } \\
\text { (ii) It has poor mechanical properties which } \\
\text { prevent from the pulverization during stirring } \\
\text { process in reactor } \\
\text { (iii) Commercial polymers are not always very } \\
\text { defined and often contain unknown impurities } \\
\text { (iv) Physical properties vary widely depending on } \\
\text { molecular weight and chemical nature }\end{array}$ \\
\hline Metal & $\begin{array}{l}\text { (i) It can induce some catalytic activity as } \\
\text { homogeneous catalyst but more selectivity } \\
\text { (ii) It is easy to separate from the product } \\
\text { (iii) It gives rise to less corrosion } \\
\text { (iv) It can be used for long periods without sign of } \\
\text { deterioration in properties }\end{array}$ & $\begin{array}{l}\text { (i) Optimization of the reaction condition is more } \\
\text { complex because there are more variables } \\
\text { (ii) leaching problem brought by the Van de Waals } \\
\text { link between the catalyst }\end{array}$ \\
\hline Carbon & $\begin{array}{l}\text { (i) It has high surface area due to porous structure } \\
\text { (ii) It has relatively small amount of chemically } \\
\text { bonded heteroatoms (mainly } \mathrm{O}_{2} \text { and } \mathrm{H}_{2} \text { ) }\end{array}$ & $\begin{array}{l}\text { It could not be used for hydrogenation reaction } \\
>700 \mathrm{~K} \text { or in the presence of } \mathrm{O}_{2}>500 \mathrm{~K} \text { because it } \\
\text { may become gasified to yield methane and } \mathrm{CO}_{2} \text {, } \\
\text { respectively }\end{array}$ \\
\hline Dendrimer & $\begin{array}{l}\text { (i) It coordinates strongly with metal catalyst } \\
\text { (ii) It leads to recyclable catalyst system and does } \\
\text { not suffer from mass transfer limitation } \\
\text { (iii) It has well-defined macromolecular structure } \\
\text { to precisely control catalyst support } \\
\text { (iv) Uniform distribution }\end{array}$ & $\begin{array}{l}\text { (i) It suffers from diminished activity due to the } \\
\text { reduction in accessibility accessibility } \\
\text { (ii) It depends on swelling properties influenced } \\
\text { by catalytic performance }\end{array}$ \\
\hline
\end{tabular}

as a support for heterogeneous catalysts which guarantees stability in electrochemical environment and commercial availability [45]. Meanwhile, strong interactions between the catalytic particles and mesoporous $\mathrm{TiO}_{2}$ have been recorded, which, in the end, resulted in both improved catalytic stability and activity. $\mathrm{TiO}_{2}$ as a catalyst support material also indicated a certain degree of proton conductivity, which may potentially enhance the regime of the triple phase boundary for catalytic reactions [44-46]. In general, the advantages and disadvantages of the other heterogeneous catalyst system are listed in Table 1 .

3.1. $\mathrm{TiO}_{2}$ : As Support in Metal Heterogeneous Catalysis. The study of metal nanoparticle on $\mathrm{TiO}_{2}$ support is important in heterogeneous catalysis due to the size and nature of the interaction of a metal nanoparticle with $\mathrm{TiO}_{2}$ support [45]. This interaction strongly influences the determination of catalytic activity and selectivity of the metal heterogeneous catalyst [46]. Reduction and oxidation at elevated temperature are compulsory steps in the preparation of metal supported $\mathrm{TiO}_{2}$ heterogeneous catalysts $[47,48]$. However, both treatments caused morphological changes to the dispersed metal nanoparticles from the sintering of $\mathrm{TiO}_{2}$. Therefore, it is important that the optimal conditions for catalyst supported $\mathrm{TiO}_{2}$ preparation be optimized, both in terms of pretreatment and activation $[48,49]$. Besides, depending on the particular metal heterogeneous catalyst, different morphological changes will result from metal- $\mathrm{TiO}_{2}$ support interaction [5052], such as sintering [50], alloy formation [52] encapsulation, and interdiffusion [51].
Among the $\mathrm{TiO}_{2}$ modifications, anatase is frequently utilized as a catalyst support for metal heterogeneous catalyst due to its high specific surface area and strong interaction with metal nanoparticles $[37,40]$. There are only a few studies reporting a rutile catalyst support which resulted in higher catalytic activity compared to anatase, such as the oxidation of toluene, xylene, and benzene over rutilesupported $\mathrm{Cu}$ catalyst. In comparison, rutile is preferred as a model support for particles of metals in surface science studies [53-55], due to its high crystal phase's thermodynamic stability. Furthermore, it is indicated that rutile and anatase differ noticeably in their ability of fixing particles of metals onto their respective surface $[49,55]$; whereas the strong metal support interaction is normally shown on anatase, this effect is not as significant on rutile. Inopportunely, the thermodynamic stability of $\mathrm{TiO}_{2}$ is comparatively low, and calcination would usually lead to the collapse of the porous structures [54]. Additionally, it is reported that calcination above $465^{\circ} \mathrm{C}$ has always resulted in the phase transition from anatase to rutile [36]. The phase transition could be connected to the growth of crystal size, which results in a severe reduction in specific surface area [35]. Consequently, this should also influence the overall catalytic performance of metal heterogeneous catalysts.

3.1.1. $\mathrm{Au} / \mathrm{TiO}_{2}$ Heterogeneous Catalyst. Gold ( $\left.\mathrm{Au}\right)$ is an excellent catalyst for the oxidation of alcohol by molecular $\mathrm{O}_{2}$ in the liquid phase with high activity, selectivity, and promising resistance to deactivation [56-58]. The catalytic performance of $\mathrm{Au}$ heterogeneous catalyst is mainly determined via the 
particle size and properties of the support [57]. Amongst all catalyst supports, $\mathrm{TiO}_{2}$ was determined to be a good support for the Au heterogeneous catalyst system due to the strong interaction in metal support, chemical stability, and acid-base properties $[44,46]$.

Au-supported $\mathrm{TiO}_{2}$ nanoparticle has been prepared by changing the several different synthesis parameters, including precipitation $\mathrm{pH}$, drying pretreatment, $\mathrm{Au}$-cluster size/morphology, catalyst conditions, the nature of the support, acid-base treatment of $\mathrm{TiO}_{2}$ support, loading of $\mathrm{TiO}_{2}$ nanoparticle, incorporation of impurities, $\mathrm{CO}$ adsorption, catalytic reaction conditions, and chemical/electronic state in catalysts $[53,58]$. The valence band of $\mathrm{Au} / \mathrm{TiO}_{2}$ indicates the presence of the Au 5d band, with a significant contribution to the $\mathrm{O} 2 \mathrm{p}$ nonbonding states, which probably is derived from $\mathrm{TiO}_{2}$ structure [46]. Therefore, the morphology images showed an interaction among the particles of $\mathrm{Au}$ with $\mathrm{TiO}_{2}$ support affecting the $\mathrm{Ti}-\mathrm{O}$ bonds at the surface, which leads to a lower Ti $2 \mathrm{p}$ binding energy in an intact $\mathrm{Au} / \mathrm{TiO}_{2}$ compared to native $\mathrm{TiO}_{2}$ (Figure 1) [59-62]. Generally, Au nanoparticles, as a catalyst, have a negative charge [57]. This is due to the electron transfer from oxygen vacancies of the $\mathrm{TiO}_{2}$ acting as a catalyst support [58].

The transformation was clearly observed in the case of acetate to ketenylidene reaction [60] (Figure 2). Thus, the charge density and level binding energy of $\mathrm{Au}$ is 0.15$0.45 \mathrm{eV}$ lower than that in pure $\mathrm{Au}$ [56]. It is concluded that the presence of $\mathrm{TiO}_{2}$ as a support in $\mathrm{Au}$ is necessary for the crystallization of the support. This, in turn, reduces the number of $\mathrm{Ti}-\mathrm{OH}$ functions to be proportional to the deposition of $\mathrm{Au}[60]$.

The aforementioned theory brought about the next advantage of $\mathrm{Au} / \mathrm{TiO}_{2}$ hybrid catalyst. The incorporation of $\mathrm{Au}$ is believed to prevent radiation-induced changes in the $\mathrm{Au} / \mathrm{TiO}_{2}$ heterogeneous catalyst composition, particularly for as-synthesized and dried samples $[63,64]$. For example, $\mathrm{X}$ ray irradiation limits a detectable further reduction in the $\mathrm{Au} / \mathrm{TiO}_{2}$ due to the presence of $\mathrm{Au}^{3+}$ state and binding energy of the Au itself [57]. The binding energy and half-width of the $\mathrm{Au} 4 \mathrm{f}_{7 / 2}$ spectra of Au particles deposited on the $\mathrm{TiO}_{2}$ in a range of concentrations were sensitive to irradiation. Indeed, the local heating mechanism occurred at higher X-ray concentrations [65]. Exposure of $\mathrm{Au} / \mathrm{TiO}_{2}$ heterogeneous catalyst to $\mathrm{X}$-ray irradiation induces the breaking of Ti-O bonds, $\mathrm{Ti}^{4+}$ state reduction, and the $\mathrm{O}_{2}$ desorption from the surface layer [64-66]. This is demonstrated by an increase in the fraction of $\mathrm{Ti}^{3+}$ species, a nonmonotonic diminution of the $\mathrm{O}_{2}{ }^{-} / \mathrm{Ti}^{4+}$ atomic ratio, improvement of the valence band, and the resultant variation of core binding energy [65]. Even though Ti $2 p$ and $\mathrm{O}$ 1s binding energies in $\mathrm{TiO}_{2}$ remain almost unaffected under extended X-ray irradiation, in $\mathrm{Au} / \mathrm{TiO}_{2}$, a gradual increase in the Ti $2 p$ binding energy is observed [67]. Thus, the effect of X-ray irradiation of $\mathrm{Au} / \mathrm{TiO}_{2}$ is relatively smaller than $\mathrm{Au}$ due to the direct evidence for charge transfer processes triggered by the production of $\mathrm{O}_{2}$ vacancies in $\mathrm{TiO}_{2}$ as a catalyst support $[63,64]$.

Many scientists have documented that $\mathrm{Au} / \mathrm{TiO}_{2}$, as a heterogeneous catalyst, showed higher reaction activities for the oxidation of primary alcohols to carboxylic acid compared to Au/zeolite [68]. The comparative study of $\mathrm{CO}$ oxidation reaction and deactivation behavior between the mesoporous $\mathrm{Au} / \mathrm{TiO}_{2}$ and $\mathrm{Au}$ demonstrated that $\mathrm{Au} / \mathrm{TiO}_{2}$ has greater catalytic selectivity and activity due to its higher surface area. Another study found that the deposition of $\mathrm{Au}$ into $\mathrm{TiO}_{2}$ led to the highly active heterogeneous catalyst for the oxidation of methanol [69-71]. The catalytic performance was determined to increase with Au loading, provided that the deposited particle size remained unchanged [70-72]. In this case, the methoxy species bound to the oxide surface are reasonable reaction intermediates, with the formation of significant bound on $\mathrm{TiO}_{2}$ [71]. The catalytic performance was correlated with the number of $\mathrm{Au}$ atoms. Thus, the methanol oxidation occurs at the interface with $\mathrm{O}_{2}$ being activated at $\mathrm{Au}$ nanoparticle and the oxide acting as a reservoir of methoxy species (Figure 3 ) [73-75].

Furthermore, there are several reports on the catalytic application of $\mathrm{Au} / \mathrm{TiO}_{2}$ on the removal of $\mathrm{CO}$ and $\mathrm{NO}_{x}$. Most of these reports investigated the catalytic and photocatalytic of $\mathrm{Au} / \mathrm{TiO}_{2}$ in the gas and liquid phase reactions, as well as their reaction mechanisms [74]. In other studies a higher stability was observed for $\mathrm{Au} / \mathrm{TiO}_{2}$ heterogeneous catalyst compared to $\mathrm{Au} / \mathrm{Co}_{3} \mathrm{O}_{4}$, which indicates a comparatively fast deactivation [70,72]. This is supported by the aforementioned report; a significant enhancement in the stability of $\mathrm{Au}$ particles against calcination can be realized by utilizing $\mathrm{TiO}_{2}$ as a catalyst support [71]. With these promising properties, $\mathrm{Au} / \mathrm{TiO}_{2}$ catalyst was also found to catalyze the epoxidation of propylene, hydrogenation reaction, water-gas shift reaction, and the oxidation of alkanes [68-76].

Meanwhile, the porosity and phase transformation are other factors that affect the catalytic performance of $\mathrm{Au} / \mathrm{TiO}_{2}$ as a heterogeneous catalyst [77, 78]. It is estimated that various $\mathrm{TiO}_{2}$ crystalline phases, as a catalyst support, could affect the interaction of support-metal, electronic density, oxidation state, Au-size, and $\mathrm{Au}$ dispersion of deposit material in heterogeneous catalyst system. In a comparative study of the activity of porous and nonporous $\mathrm{Au} / \mathrm{TiO}_{2}$, heterogeneous catalyst prepared from different crystalline phase of $\mathrm{TiO}_{2}$ included the anatase, rutile, and rutile+anatase $[69,79]$. For example, certain studies found that the activity of nonporous $\mathrm{Au} / \mathrm{TiO}_{2}$ heterogeneous catalyst decreased from brookite via anatase to rutile for catalyst activated by calcination at $300^{\circ} \mathrm{C}$, while, after reduction at $150^{\circ} \mathrm{C}$, the activities became rather comparable $[80,81]$. Similar observation was reported by other studies for mesoporous $\mathrm{TiO}_{2}$ acting as support for $\mathrm{Au}$ heterogeneous catalyst [82]. The tendency in the increment for $\mathrm{Au}$ particle sintering during calcination at $300^{\circ} \mathrm{C}$ is brookite, anatase, and rutile, followed by mesoporous. In contrast, such effect is insignificant at the reduction of $150^{\circ} \mathrm{C}$ [82]. Some studies reported that the crystalline phase of $\mathrm{TiO}_{2}$ influences also the deactivation of $\mathrm{Au} / \mathrm{TiO}_{2}$ heterogeneous catalyst with comparable surface area of $46-54 \mathrm{~m}^{2} \mathrm{~g}^{-1}$, increased in the order of $\mathrm{Au} / \mathrm{TiO}_{2}$ anatase and $\mathrm{Au} / \mathrm{TiO}_{2}$ nonporous rutile/anatase and followed by $\mathrm{Au} / \mathrm{TiO}_{2}$ rutile [83]. 

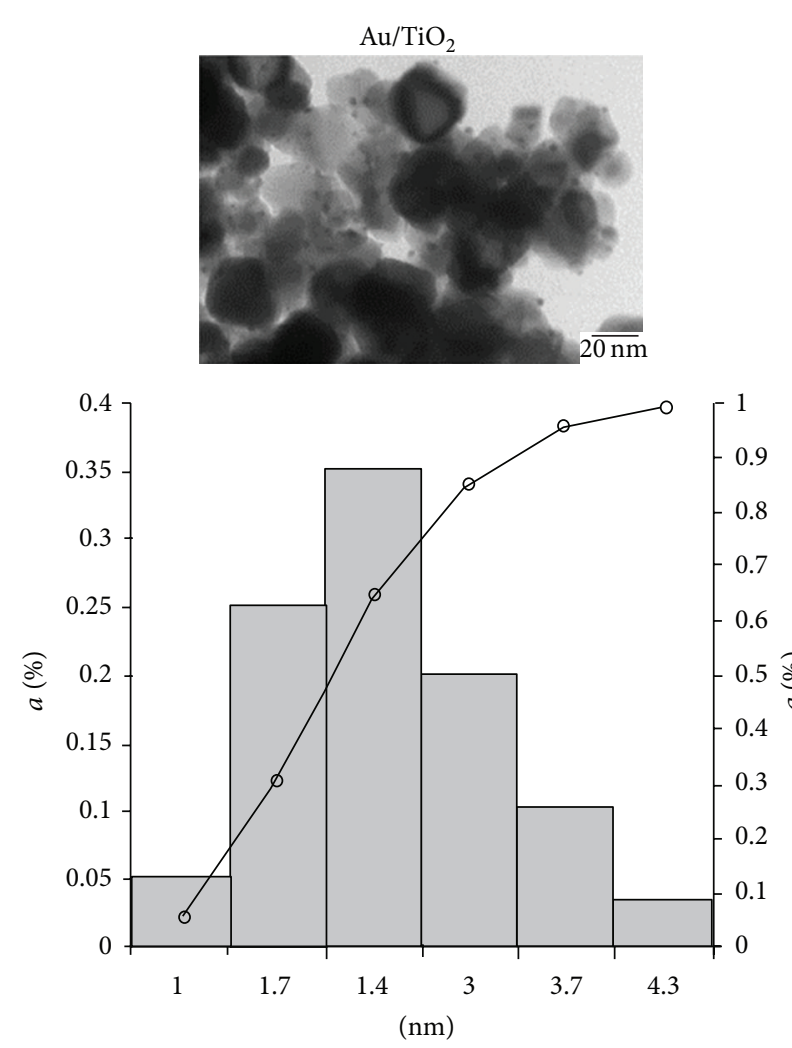

Dmoy $=2.78 \pm 0.77 \mathrm{~nm}$

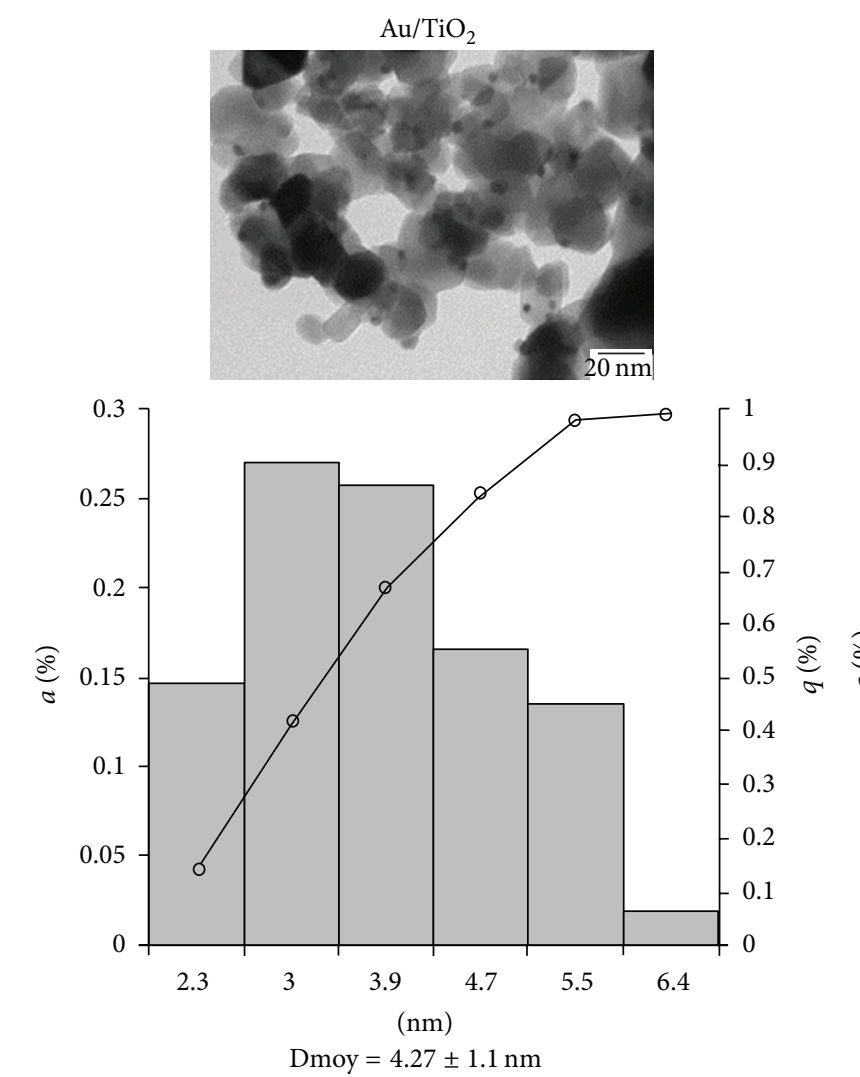

(b)

(a)
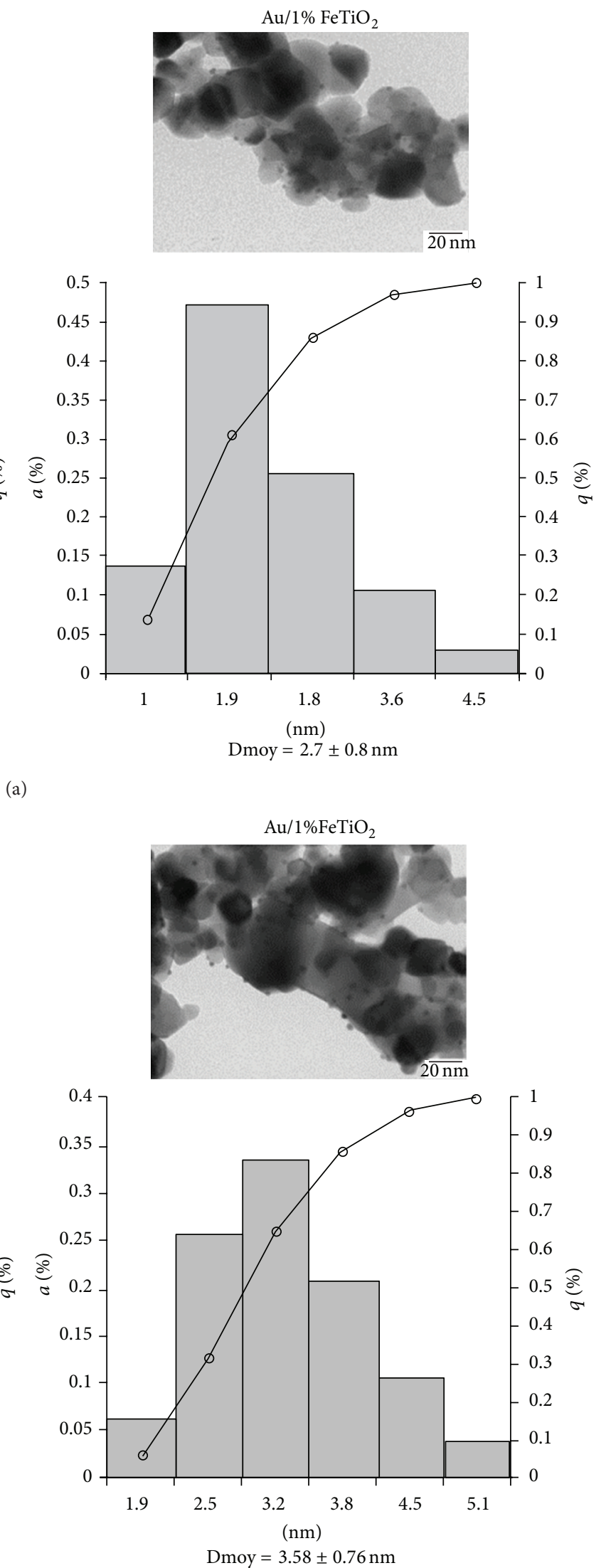

Figure 1: TEM analysis of gold supported on $\mathrm{TiO}_{2}$ and $1 \% \mathrm{FeTiO}_{2}$ before (a) and after (b) thermal treatment [59]. 


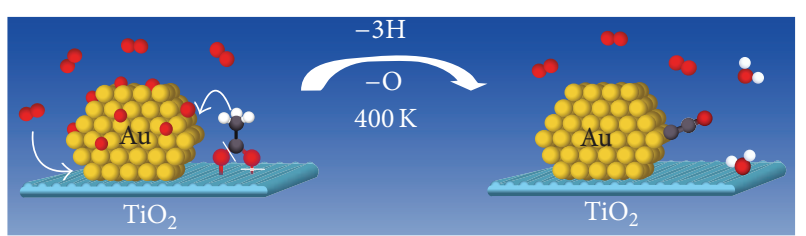

FIgURE 2: This shows the conversion of acetate to ketenylidene at the perimeter site of the $\mathrm{Au} / \mathrm{TiO}_{2}$ catalyst. The acetate, which adsorbs on $\mathrm{TiO}_{2}$, undergoes dehydrogenation (oxidation) and the deoxygenation to form ketenylidene on the gold [60].

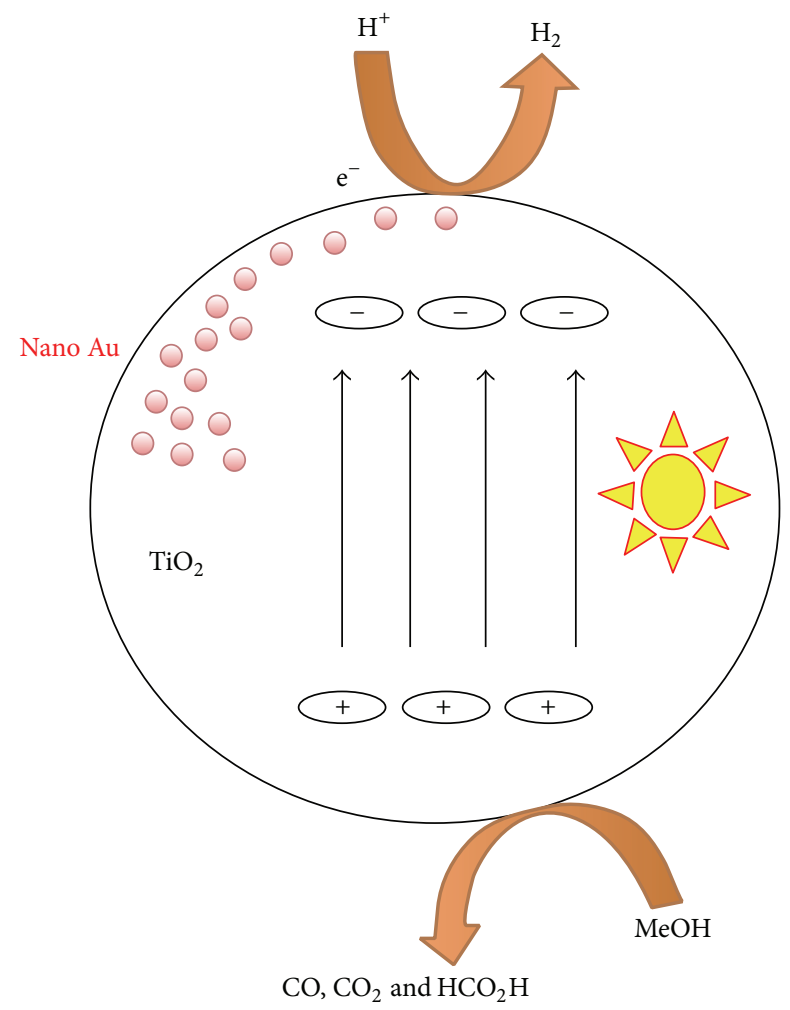

FIgURE 3: $\mathrm{Au} / \mathrm{TiO}_{2}$ catalysts, easily prepared in situ from different Au precursors and $\mathrm{TiO}_{2}$, generate $\mathrm{H}_{2}$ from $\mathrm{H}_{2} \mathrm{O}$ /alcohol mixtures [73].

Contrarily, some studies concluded that the crystalline phase has no significant influence on the catalytic performance of the unconditioned $\mathrm{Au} / \mathrm{TiO}_{2}$ heterogeneous catalyst [84]. This was different, as the $\mathrm{Au} / \mathrm{TiO}_{2}$ heterogeneous catalyst was calcined prior to the reaction, where the $\mathrm{Au} / \mathrm{TiO}$ rutile+anatase heterogeneous catalyst indicated a significantly higher stability than $\mathrm{Au} / \mathrm{TiO}_{2}$ rutile and $\mathrm{Au} / \mathrm{TiO}_{2}$ anatase [85]. After calcination at $250^{\circ} \mathrm{C}$, the activities are comparable to those of the unconditioned heterogeneous catalyst and are similar for all catalysts. However, calcination at $350^{\circ} \mathrm{C}$ leads to lower activities for the mesoporous rutile or anatase, while the rutile+anatase supported $\mathrm{Au}$ retains its respective activities [83]. The catalytic performance of Au-supported $\mathrm{TiO}_{2}$ anatase being superior to other heterogeneous catalyst was examined for the decrease of $\mathrm{NO}_{x}$ using propane due to the smaller size of the Au particles on $\mathrm{TiO}_{2}$ anatase $[86,87]$.
Although $\mathrm{Au} / \mathrm{TiO}_{2}$ is active as a heterogeneous catalyst, it often complied with quick deactivate process which limits its commercial applications [70-74]. In general, in order for the Au particle to indicate higher performance at near subambient temperatures, its cluster size has to be less than $5 \mathrm{~nm}$ [65]. Therefore, some attempt has to be made to synthesize $\mathrm{Au}$ hydroxide $\left[\mathrm{AuO}_{x}(\mathrm{OH})_{4-2 x}\right]_{n}$ deposited on the $\mathrm{TiO}_{2}$ support, followed by drying in the air. The idea is to prevent the in situ formation and the agglomeration of metallic Au nanoparticles, as seen with coprecipitation [64]. Another approach is by synthesizing nearly monodispersed thiol-protected $\mathrm{Au}$ nanoparticles and is deposited into $\mathrm{TiO}_{2}$ as a support. In this case, the thiol ligands were utilized to control the size of the cluster $[82,88]$. The advantages offered by both methods included a better control size of Au nanoparticle due to ex situ synthesis and the formation of Au cluster in the solution prior to the deposition on the $\mathrm{TiO}_{2}$ as a catalyst support [88].

In conclusion, the most common factors affecting the $\mathrm{Au} / \mathrm{TiO}_{2}$ heterogeneous catalyst activity are the size of the $\mathrm{Au}$ nanoparticles, preparation method, pretreatment method, $\mathrm{Au}$ loading, the oxidation state of $\mathrm{Au}$, and the binding strength to $\mathrm{TiO}_{2}$ as a catalyst support.

3.1.2. $\mathrm{Co} / \mathrm{TiO}_{2}$ Heterogeneous Catalyst. The activity of cobalt supported $\mathrm{TiO}_{2}\left(\mathrm{Co} / \mathrm{TiO}_{2}\right)$ heterogeneous catalyst is greatly related to the $\mathrm{TiO}_{2}$ crystal phase and the loading of $\mathrm{Co}^{3+}$ ions on the catalyst support [89-91]. The case of $\mathrm{Co} / \mathrm{TiO}_{2}, \mathrm{TiO}_{2}$ in the rutile phase is more appropriate as a catalyst support material than those with a $100 \%$ anatase phase $[25,90]$. Therefore, $\mathrm{Co} / \mathrm{TiO}_{2}$ heterogeneous catalyst synthesized with more than $15 \%$ rutile phase is shown to have 4 times higher $\mathrm{CO}$ conversion rate than those that only consist of the anatase phase $[92,93]$. Furthermore, the $\mathrm{Co} / \mathrm{TiO}_{2}$, when modified with alkaline earth metals, resulted in a greater $\mathrm{CO}$ conversion rate, whereas modification with $\mathrm{Mn}$ and $\mathrm{V}$ resulted in high $\mathrm{C}^{5+}$ and low methane selectivity, respectively [9496]. Furthermore, with only $0.8 \% \mathrm{Ca}$ modification, $\mathrm{Co} / \mathrm{TiO}_{2}$ obtained the highest $\mathrm{CO}$ conversion rate and site-time yield of $\mathrm{C}^{5+}$ products. The conversion rate is 1.3-1.5 times higher than cosupported $\mathrm{SiO}_{2}$ catalyst (Figure 4) [97]. Therefore, the CO conversion reaction rate over $\mathrm{Co} / \mathrm{TiO}_{2}$ catalyst was proportionately amplified by increasing the surface area of Co [93].

Actually, the production of highly dispersed $\mathrm{Co}$ on $\mathrm{TiO}_{2}$ as a catalyst support requires a strong interaction [91, 92]. Nevertheless, too strong of an interaction generates the $\mathrm{TiO}_{2}$ compound as a suboxide at an interface, which is highly resistant to reduction [89]. In this case, while it has known that the dominant surface sites of $\mathrm{TiO}_{2}$ support consist of two main sites, which are $\mathrm{Ti}^{3+}$ and $\mathrm{Ti}^{4+}$, the surface site's effect on the formation of $\mathrm{Co}$ to $\mathrm{TiO}_{2}$ interface indicates that the reaction should be structured to be insensitive and based on the number of the exposed Co metal sites [93-99]. It is also proposed that this growth in the reaction rate might be due to the strong Co to $\mathrm{TiO}_{2}$ interaction altering the catalytic properties [100].

3.1.3. $\mathrm{Ni} / \mathrm{TiO}_{2}$ Heterogeneous Catalyst. Nickel (Ni) supported $\mathrm{TiO}_{2}\left(\mathrm{Ni} / \mathrm{TiO}_{2}\right)$, as a heterogeneous catalyst, is another kind 


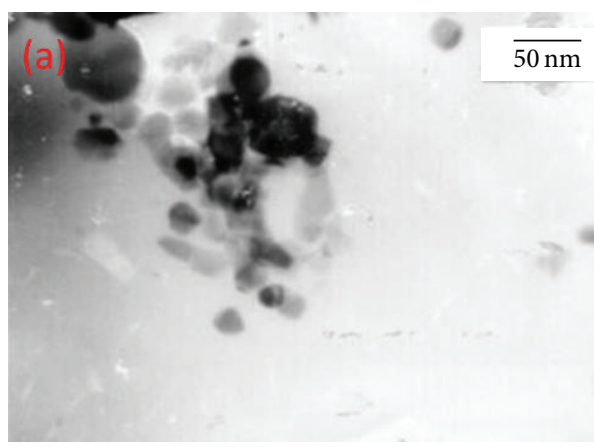

(a)

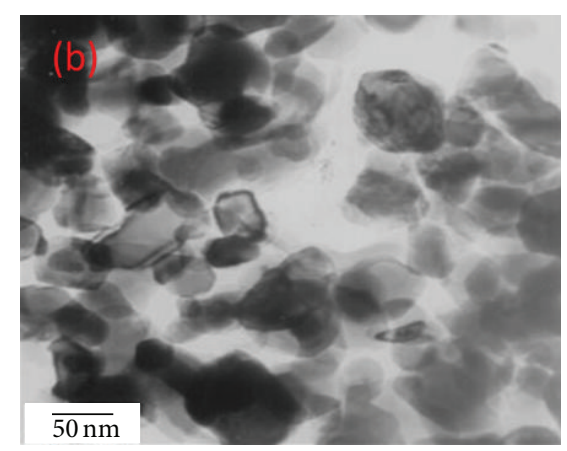

(b)

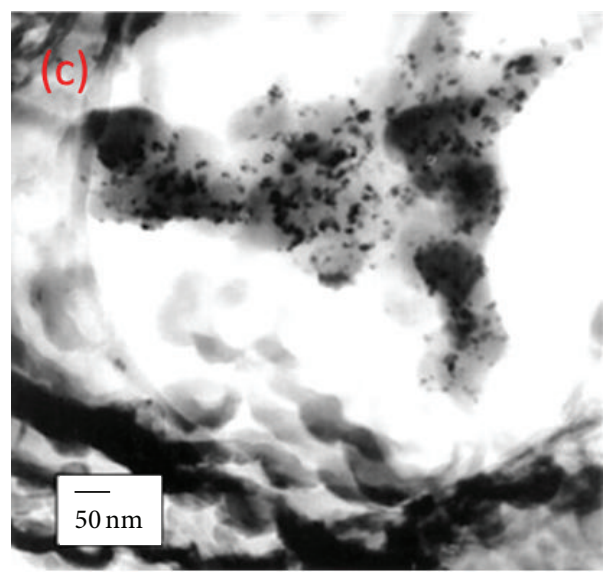

(c)

FIgURE 4: (a) TEM micrograph of $\mathrm{Co} / \mathrm{TiO}_{2}$ (673)-I catalyst after reduction-oxidation-reduction cycle at 773-623-623 K. (b) TEM micrograph of $\mathrm{Co} / \mathrm{TiO}_{2}$ (973)-I catalyst after reduction-oxidation-reduction cycle at 773-623-773. (c) TEM micrograph of Co/TiO 2 (673)-SG catalyst after reduction-oxidation-reduction cycle at 773-623-773 K [97].

of important Ni-based catalyst. This is due to the strong interaction between $\mathrm{Ni}$ as a metal and $\mathrm{TiO}_{2}$ as a catalyst support [101-103]. For example, the catalytic properties of supported $\mathrm{Ni} / \mathrm{TiO}_{2}$ heterogeneous catalysts prepared by the incipient wetness impregnation method were evaluated for the vapor phase hydrogenation of maleic anhydride [104]. It was discovered that the hydrogenation process of maleic anhydride is strongly affected by the calcination temperature of $\mathrm{Ni} / \mathrm{TiO}_{2}$. The $\mathrm{Ni} / \mathrm{TiO}_{2}$ heterogeneous samples recorded an optimum catalytic performance with $96 \%$ maleic anhydride conversion as the calcination temperature reached $1023 \mathrm{~K}[104,105]$. This is attributed to the change of surface properties of $\mathrm{TiO}_{2}$ support to the increase of calcination temperature. In addition, the strong metal support interaction between $\mathrm{Ni}$ and rutile surface over $\mathrm{Ni} / \mathrm{TiO}_{2}$ catalyst was the key reason for the better activity of the catalyst in acetophenone hydrogenation [105]. However, the deactivation of $\mathrm{Ni} / \mathrm{TiO}_{2}$ heterogeneous catalyst occurred as the carbonaceous species of maleic anhydride was deposited onto the Ni surface $[106,107]$. To regenerate the catalytic performance of $\mathrm{Ni} / \mathrm{TiO}_{2}$, thermal treatment in the oxidant atmosphere approach is applied.

3.1.4. $\mathrm{Pd} / \mathrm{TiO}_{2}$ Heterogeneous Catalyst. Anatase $\mathrm{TiO}_{2}$ effectively engenders $\mathrm{OH}$ species. Thus, palladium-supported
$\mathrm{TiO}_{2}\left(\mathrm{Pd} / \mathrm{TiO}_{2}\right)$ anatase possesses excellent catalytic activity vis-à-vis methanol electrooxidation. There are some reports claiming that $\mathrm{Pd}$-supported $\mathrm{TiO}_{2}$ anatase heterogeneous catalyst demonstrated a greater activity than $\mathrm{TiO}_{2}$ rutile in selective hydrogenation reactions due to the superior metal supporting the behavior of $\mathrm{TiO}_{2}$ anatase [108-112]. Consequently, negligible $\mathrm{CO}$ intermediates are produced in direct formic acid fuel cells and formic acid electrooxidation, which consequently possess striking catalytic activity. In contradiction, the acetoxylation of toluene study indicates that $\mathrm{Pd}$ supported by rutile $\mathrm{TiO}_{2}$ has greater selectivity of almost $100 \%$ without any deactivation of the catalyst compared to the ones supported by anatase [110-113], due to the high thermal stability of rutile. Meanwhile, the treatment of $\mathrm{Pd} / \mathrm{TiO}_{2}$ anatase heterogeneous catalyst by an $\mathrm{H}_{2}$ reduction at $200^{\circ} \mathrm{C}$ resulted in greater reactivity in hydrogenation of alkadienes than that of the $\mathrm{Pd} / \mathrm{TiO}_{2}$ in rutile phase [112]. The strong metal support interaction was only observed in the anatase phase of supported Pd heterogeneous catalyst [109, 110]. There is also an attempt to synthesize the genesis of the Pd cluster on $\mathrm{TiO}_{2}$-grafted $\mathrm{SiO}_{2}$. The results showed that $\mathrm{TiO}_{2}$ anchors $\mathrm{Pd}$ particles during air calcination and maintains its small ensemble during $\mathrm{H}_{2}$ reduction [114, 115]. These observations serve to demonstrate how $\mathrm{TiO}_{2}$, as a catalyst 
support, influences the structure and catalytic performance, specifically for sulfur-resistant catalysts [114]. It was also concluded that $\mathrm{TiO}_{2}$-grafted $\mathrm{SiO}_{2}$ offers better support due to the presence of high surface area and thermal stability for $\mathrm{Pd}$ heterogeneous catalyst compared to pure $\mathrm{TiO}_{2}$ [116-118].

3.1.5. $\mathrm{Pt} / \mathrm{TiO}_{2}$ Heterogeneous Catalyst. The dispersion and loading of platinum (Pt) nanoparticles onto $\mathrm{TiO}_{2}$ support is controlled by the structure and porosity of $\mathrm{TiO}_{2}$. Consequently, a suitable combination of passable electronic conductivity and nanostructured morphology with controlled porosity could result in very promising $\mathrm{Pt} / \mathrm{TiO}_{2}$ heterogeneous catalysts [119-124]. For example, a novel electrocatalyst based on mesoporous $\mathrm{TiO}_{2}$ supported $\mathrm{Pt}$ nanoparticles indicates a high stability under accelerated stress test conditions and activity compared to commercial Pt-supported carbon catalyst $[121,122]$. Some studies have investigated the influence of the reductive treatment on structural properties of $\mathrm{Pt} / \mathrm{TiO}_{2}$, with their catalytic activity for formaldehyde oxidation [123]. It is claimed that the enhanced catalytic performance is reflected by a uniform dispersion of $\mathrm{Pt}$ nanoparticles and the interaction between $\mathrm{Pt}$ and $\mathrm{TiO}_{2}$ [124]. Thus, the application of $\mathrm{Pt}$ as a heterogeneous catalyst becomes more encouraging, especially in electrochemical and photoelectrochemical context $[125,126]$. For example, $\mathrm{H}_{2}$ production could be significantly improved by photocatalytic water splitting over $\mathrm{Pt} / \mathrm{TiO}_{2}$ nanosheets compared to native Pt [126].

Several methods have applied in the preparation of $\mathrm{Pt}$ nanoparticle deposited on $\mathrm{TiO}_{2}$ substrates included underpotential deposition [127-129], hydrothermal treatment [130, 131], photoassisted reduction [132], and vacuum deposition $[133,134]$. Electrodeposition would be a straightforward approach for the synthesis of Pt-supported $\mathrm{TiO}_{2}$, which is highly required for the production of complex electrode architectures in fuel cells [132-134]. This in turn resulted in the $\mathrm{H}_{2}$ evolution rate of $3 \mathrm{wt} \% \mathrm{Pt} / \mathrm{TiO}_{2}$, which was relatively greater than that of $3 \mathrm{wt} \% \mathrm{Pt} / \mathrm{Al}_{2} \mathrm{O}_{3}$. Other studies found that $\mathrm{TiO}_{2}$, as a support material, improves $\mathrm{Pt}_{2}$ reduction activity by assisting mechanisms such as reactant surface diffusion and $\mathrm{O}_{2}$ spillover [135-137]. Furthermore, $\mathrm{Pt} / \mathrm{TiO}_{2}$ showed similar performance to $\mathrm{Pt} / \mathrm{C}$ in $\mathrm{H}_{2}$-fuel cell operated at $60^{\circ} \mathrm{C}$ and $0.8 \mathrm{~V}$ (Figure 5) [136].

Certain studies on the effect of particle size indicated that amorphous $\mathrm{TiO}_{2}$ could powerfully suppress the $\mathrm{O}_{2}$ reduction reaction activity of supported $\mathrm{Pt}$ at smaller sizes [138-140]. For example, a series of $\mathrm{Pt} / \mathrm{TiO}_{2}$ heterogeneous catalyst with various $\mathrm{Pt}$ particle sizes was prepared and tested for low temperature $\mathrm{CO}$ oxidation [139]. The result indicated that the $\mathrm{Pt} / \mathrm{TiO}_{2}$ heterogeneous catalyst that resulted in superior activity at the weight percent of $\mathrm{Pt}$ in $\mathrm{Pt} / \mathrm{TiO}_{2}$ heterogeneous catalyst was $5.0 \%$, with the complete conversion temperature being $120^{\circ} \mathrm{C}[141-143]$.

3.2. $\mathrm{TiO}_{2}$ : As Support in Metal Oxide Heterogeneous Catalysis. Metal oxides signify one of the important and broadly used categories of heterogeneous catalysts. Metal oxides are utilized for both their redox and their acid-base properties and

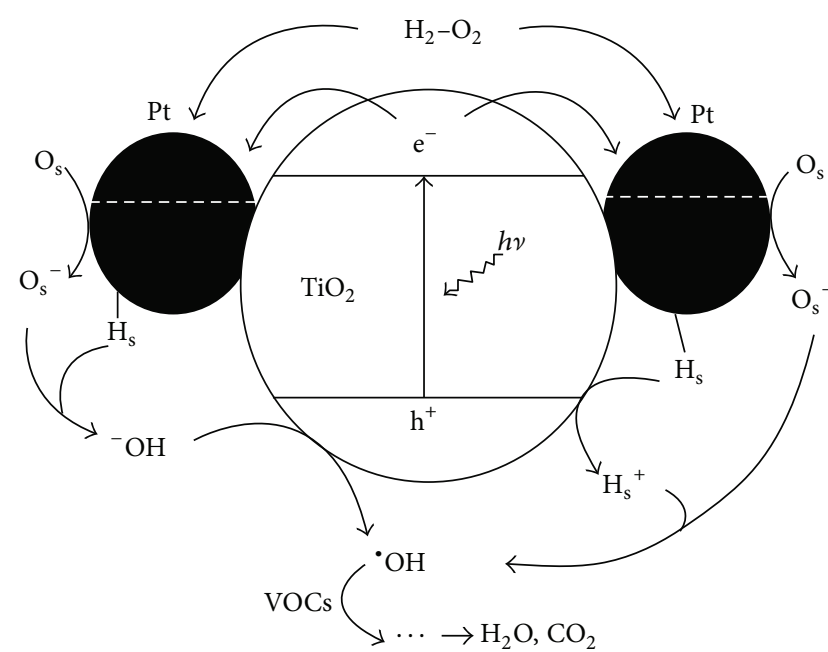

FIGURE 5: Proposed mechanism for the photochemical generation of $\mathrm{dOH}$ radicals on a $\mathrm{Pt} / \mathrm{TiO}_{2}$ catalyst in the coexistence of $\mathrm{H}_{2}$ and $\mathrm{O}_{2}$ [136].

constitute the main family of catalyst in the heterogeneous category. Furthermore, certain metal salts and organometallic compounds using a heterogeneous catalyst precursor have the tendency to be decomposed via exposure to light irradiation. Some reports show that, as the oxide-containing catalyst under light irradiation analysis needs great care, considerable damage is possible even at low irradiation dose. For catalytic applications, metal oxides have also been employed for various applications such as gas sensor, the photocatalyst thin film, and fuel cells. $\mathrm{TiO}_{2}$ is often used to modify the supported metal oxide heterogeneous catalyst due to properties such as reducible surface and possible electron transfer via the spontaneous alignment of the Fermi levels.

3.2.1. $\mathrm{CuO} / \mathrm{TiO}_{2}$ Heterogeneous Catalyst. It has been reported that copper oxide $(\mathrm{CuO})$ heterogeneous catalyst is highly active for $\mathrm{CO}$ oxidation and lower in cost compared to other noble metal heterogeneous catalysts [144-147]. CuO has additional advantages, such as a high thermal stability and the fact that it is economical [145-149]. The highest activities of $\mathrm{CuO}$ heterogeneous catalyst are attributed to the synergy between the $\mathrm{Cu}$ species and the support, especially in the case of $\mathrm{TiO}_{2}$ as support material. For example, the increment of activity for $\mathrm{CO}$ oxidation over the $\mathrm{CuO} / \mathrm{TiO}_{2}$ heterogeneous catalyst is attributed to the sites for $\mathrm{CO}$ chemisorption that is responsible for $\mathrm{O}_{2}$ activation $[150,151]$. Furthermore, since $\mathrm{CO}$ oxidation over the supported metal heterogeneous catalyst takes place at the metal support interface, $\mathrm{TiO}_{2}$, as reducible oxide, could provide the intrinsic activity to the entire reaction [149]. Therefore, only a small amount of $\mathrm{CuO}$ is loaded onto $\mathrm{TiO}_{2}$ and influence of $\mathrm{TiO}_{2}$ crystalline phase, which are indicative of the fact that the support system has higher efficiency and selectivity than the CO oxidation being examined [152].

On the other hand, $\mathrm{CuO} / \mathrm{TiO}_{2}$ heterogeneous catalyst is also found suitable for $\mathrm{NO}$ reductions [150]. Rutile $\mathrm{TiO}_{2}$ is 
the most stable phase compared to anatase and brookite, and $\mathrm{Cu}$-based heterogeneous catalysts show promising activity towards NO reduction [151]. Therefore, it is necessary and important to further approach the change of heterogeneous catalyst surface with plasma-assisted processing. NO reduction by $\mathrm{CO}$ reaction was comparatively studied over microwave plasma pretreated $\mathrm{CuO} / \mathrm{TiO}_{2}$ heterogeneous catalysts employing transmission electron microscopy, $\mathrm{H}_{2}$ temperature programmed reduction, and in situ Fourier transform infrared spectroscopy [152-154]. The $\mathrm{CuO} / \mathrm{TiO}_{2}$ heterogeneous catalytic performances indicated that a remarkable improvement in activity and selectivity was achieved after microwave plasma pretreatment, which depends on the microwave plasma pretreatment time [153]. The results also suggested that high active oxygen species are formed on the surface of plasma pretreated $\mathrm{CuO} / \mathrm{TiO}_{2}$ heterogeneous catalysts, which led to the easy oxidation of $\mathrm{NO}$ to $\mathrm{NO}_{2}$ at low temperatures even without the introduction of any additional $\mathrm{O}_{2}$ gas. Therefore, these high active oxygen species should play an important role in the exaltation of the catalytic performances of the $\mathrm{CuO} / \mathrm{TiO}_{2}$ heterogeneous catalysts [155]. It is found that $\mathrm{CuO}$ supported on the anatase phase of $\mathrm{TiO}_{2}$-support calcined at $400^{\circ} \mathrm{C}$ demonstrated better catalytic activity than those supported on $\mathrm{TiO}_{2}$ calcined at 500 or $700^{\circ} \mathrm{C}$. Among all of the investigated heterogeneous catalysts with $\mathrm{CuO}$ loading from $2 \%$ to $12 \%$, the $\mathrm{CuO} / \mathrm{TiO}_{2}$ heterogeneous catalyst with $8 \mathrm{wt} \% \mathrm{CuO}$ loading exhibited the highest catalytic activity [156]. The optimum calcination temperature of the $\mathrm{CuO} / \mathrm{TiO}_{2}$ heterogeneous catalysts was recorded at $300^{\circ} \mathrm{C}$

$\mathrm{CuO} / \mathrm{TiO}_{2}$ is also known as a promising heterogeneous catalyst in the photocatalytic applications. Whilst it is widely recognized that $\mathrm{CuO}$ facilitates charge separation and acts as a $\mathrm{H}_{2} \mathrm{O}$ reduction site, conjecture still exists as to the exact nature of the dispersed $\mathrm{CuO}$, specifically on $\mathrm{TiO}_{2}$ and the optimum $\mathrm{CuO}$ loading for efficient $\mathrm{H}_{2}$ production [157, 158]. The surface chemistry of the $\mathrm{CuO} / \mathrm{TiO}_{2}$ heterogeneous catalyst is the subject of a number of investigations to explain the excellent activity of the photocatalysts. It is generally recognized that $\mathrm{CuO}$ exists in several different forms on $\mathrm{TiO}_{2}$, with the specification depending on the $\mathrm{CuO}$ content and catalyst pretreatment conditions [159]. Experimental evidence suggested that, at low $\mathrm{CuO}$ loadings, $\mathrm{Cu}^{2+}$ is highly dispersed on $\mathrm{TiO}_{2}$ as a surface complex or $\mathrm{CuO}$ monolayer. This, in turn, can easily reduce the $\mathrm{CO}$ or $\mathrm{H}_{2}$ at low temperatures [150]. For example, $\mathrm{CuO} / \mathrm{TiO}_{2}$ photocatalyst is very active in the reduction of water under sacrificial conditions (95 vol. $\% \mathrm{H}_{2} \mathrm{O}, 5$ vol. $\% \mathrm{CH}_{3} \mathrm{OH}$ ) and UV excitation, with the optimal $\mathrm{CuO}$ loading of 5 to $10 \mathrm{wt} \%$ of the heterogeneous catalyst system [153]. The high catalytic activity caused photo-citation of electrons in the conduction bands of both $\mathrm{CuO}$ and $\mathrm{TiO}_{2}$, followed by the migration of the conduction band electrons in $\mathrm{TiO}_{2}$ into the conduction band of $\mathrm{CuO}$ heterogeneous catalyst $[155,156]$. The accumulation of excess electrons in the conduction band of $\mathrm{CuO}$ caused a negative shift in the Fermi level of $\mathrm{CuO}$ to give the required overvoltage necessary for $\mathrm{H}_{2} \mathrm{O}$ reduction [154]. However, once the $\mathrm{CuO}$ loading exceeds the dispersion capacity, nanocrystalline of the $\mathrm{CuO}$ begins to form. $\mathrm{CuO}$ is itself inactive for $\mathrm{H}_{2}$ production from water or alcoholwater mixtures under UV or visible irradiation, since the conduction band of $\mathrm{CuO}$ is more positive than the $\mathrm{H}_{2} \mathrm{O} / \mathrm{H}_{2}$ redox potential [160-162]. Accordingly, the onset of the $\mathrm{CuO}$ nanoparticle formation should coincide with a decrease in the photocatalytic activity of $\mathrm{CuO} / \mathrm{TiO}_{2}$ photocatalysts for $\mathrm{H}_{2}$ production, as the presence of inert $\mathrm{CuO}$ nanoparticles will reduce the number of surface sites on $\mathrm{TiO}_{2}$ available for photoreactions $[161,162]$. Experimental evidence to support this hypothesis is currently lacking, which motivates the present investigation.

$\mathrm{CuO} / \mathrm{TiO}_{2}$ heterogeneous catalyst could be synthesized by a deposition-precipitation method. For example, $\mathrm{CuO}$ has been deposited on $\mathrm{TiO}_{2}$ nanotubes with $\mathrm{Cu} / \mathrm{Ti}$ atom ratio of 10 and then evaluated by $\mathrm{H}_{2}$ generation activity in methanol $\mathrm{H}_{2} \mathrm{O}$ mixtures under UV excitation. It is reported that the optimal $\mathrm{CuO}$ loading is around $1.3 \mathrm{wt} \%$, giving the $\mathrm{H}_{2}$ production rate of $2061 \mu \mathrm{molg}^{-1} \mathrm{~h}^{-1}$ [161]. Meanwhile, the $\mathrm{CuO} / \mathrm{TiO}_{2}$ heterogeneous catalyst prepared by a complex precipitation method indicates the highest $\mathrm{H}_{2}$ production observed in $10 \mathrm{wt} \%$ of the $\mathrm{CuO}$ loading [162]. Another study evaluated the performance of $2.5 \mathrm{wt} \% \mathrm{CuO}-\mathrm{TiO}_{2}$ photocatalyst for $\mathrm{H}_{2}$ production from methanol and found that 27$29 \%$ of $\mathrm{H}_{2}$ evolution at rate of $1350 \mu \mathrm{mol} \mathrm{g}^{-1} \mathrm{~h}^{-1}$ is produced for ethanol- $\mathrm{H}_{2} \mathrm{O}$ mixture of $900-1000 \mathrm{~g}^{-1} \mathrm{~h}^{-1}[158,159]$. It was recorded that $1 \mathrm{wt} \% \mathrm{CuO} / \mathrm{TiO}_{2}$ photocatalyst is active for $\mathrm{H}_{2} \mathrm{O}$ splitting under visible light in the presence of triethanolamine.

3.2.2. $\mathrm{V}_{2} \mathrm{O}_{5} / \mathrm{TiO}_{2}$ Heterogeneous Catalyst. Initially, vanadium oxide $\left(\mathrm{V}_{2} \mathrm{O}_{5}\right)$ supported $\mathrm{TiO}_{2}$ heterogeneous catalyst was applied for the o-xylene oxidation to phthalic anhydride reaction. Then, the potential of $\mathrm{V}_{2} \mathrm{O}_{5} / \mathrm{TiO}_{2}$ was recorded in the pollution abatement of $\mathrm{NO}$ with $\mathrm{NH}_{3}$ process $[163,164]$. Thus, $\mathrm{V}_{2} \mathrm{O}_{5} / \mathrm{TiO}_{2}$ is one of the most efficient catalysts in the oxidative dehydrogenation of propane, with only a few byproducts [165]. A stable deposit of $\mathrm{TiO}_{2}$ in $\mathrm{V}_{2} \mathrm{O}_{5} / \mathrm{TiO}_{2}$ heterogeneous catalyst system was established with dip coating of $\mathrm{V}_{2} \mathrm{O}_{5}$ in an aqueous suspension of titanium isopropoxide $[166,167]$.

Furthermore, $\mathrm{V}_{2} \mathrm{O}_{5} / \mathrm{TiO}_{2}$ heterogeneous catalyst found another promising application in the dehydrogenation of alkanes and selective oxidation of alcohols/alkanes [168]. In this respect, the activity and product distribution of the heterogeneous catalyst for methanol oxidation strongly depend on its surface acidity and redox ability, and this can be regulated through proper modifications [169]. The heterogeneous catalyst of $\mathrm{V}_{2} \mathrm{O}_{5}$ supported on $\mathrm{TiO}_{2}$ exhibited high conversion of methanol and selectivity of dimethylmethane for the oxidation of methanol under mild conditions [170]. The catalytic oxidation of $\mathrm{V}_{2} \mathrm{O}_{5} / \mathrm{TiO}_{2}$ heterogeneous catalyst was investigated for 1,2-dichlorobenzene [171], and it was surmised that the catalytic oxidation of 1,2-dichlorobenzene on chemical vapor condensation which prepared $\mathrm{V}_{2} \mathrm{O}_{5} / \mathrm{TiO}_{2}$ heterogeneous catalyst demonstrated excellent performance at lower temperatures [171]. The surface structure of $\mathrm{TiO}_{2}$ allows the development of the Lewis acidity, as well as redox 
properties. Consequently, redox properties $\mathrm{TiO}_{2}$ modified by the presence of $\mathrm{V}_{2} \mathrm{O}_{5}$ lead to an electronic interaction between this support and $\mathrm{V}_{2} \mathrm{O}_{5}$ species [169]. $\mathrm{V}_{2} \mathrm{O}_{5}$ loading is a key point for the activity, and it has been suggested that a single redox surface site participates in the kinetically significant steps, with the formation of crystalline $\mathrm{V}_{2} \mathrm{O}_{5}$ being detrimental to oxidation activity $[168,172]$.

The effect on surface acidity and redox ability of $\mathrm{V}_{2} \mathrm{O}_{5} / \mathrm{TiO}_{2}$ is also found to be interesting for the selective catalytic reduction by $\mathrm{NH}_{3}$. The proposed mechanism suggested that $\mathrm{NH}_{3}$ is activated and reacts from a strongly adsorbed state with gaseous or weakly adsorbed NO [173-175]. It is believed that reliable structure-activity relationship is based on the understanding of the $\mathrm{V}_{2} \mathrm{O}_{5} / \mathrm{TiO}_{2}$ heterogeneous catalyst molecular structure under operating conditions [174]. Thus, a dual-site mechanism involving a surface $\mathrm{V}_{2} \mathrm{O}_{5}$ redox site and an adjacent nonreducible site appears to be more favorable. Furthermore, the reported influence of specific oxide supports, along with the observed stability of terminal $\mathrm{V}={ }^{18} \mathrm{O}$ bonds during $\mathrm{NH}_{3}$ reaction, suggests that the $\mathrm{V}-\mathrm{O}$ support bond is involved in the rate-determining step [167169]. Similarly, the $\mathrm{NH}_{3}$ action of transition for $\mathrm{V}_{2} \mathrm{O}_{5} / \mathrm{TiO}_{2}$ heterogeneous catalyst correlates well with the extent of interactions between the active phase and the support [172]. The Raman studies of $\mathrm{V}_{2} \mathrm{O}_{5} / \mathrm{TiO}_{2}$ heterogeneous catalyst revealed that the presence of multiple structures of surface $\mathrm{V}_{2} \mathrm{O}_{5}$ species on $\mathrm{TiO}_{2}$, including monomeric and polymeric $\mathrm{V}_{2} \mathrm{O}_{5}$ species at submonolayer coverage $[175,176]$. Therefore, Raman studies of $\mathrm{V}_{2} \mathrm{O}_{5} / \mathrm{TiO}_{2}$ heterogeneous catalysts under SCR or reducing $\left(\mathrm{NH}_{3}\right)$ conditions are scarce.

The influence on preparation procedure towards surface of $\mathrm{V}_{2} \mathrm{O}_{5}$ state plays an important role in selective catalytic reduction. Some studies have investigated the surface of $\mathrm{V}_{2} \mathrm{O}_{5}$ prepared by incipient wetness impregnation, with $\mathrm{TiO}_{2}$ being a support, and found that both isolated and polymeric surface $\mathrm{V}_{2} \mathrm{O}_{5}$ species existed with medium VO surface coverage [177-179]. This is supported by other studies mentioning that polymeric $\mathrm{V}_{2} \mathrm{O}_{5}$ species demonstrated greater catalytic activity than monomeric $\mathrm{V}_{2} \mathrm{O}_{5}$ [178]. This is due to the greater mobility of lattice $\mathrm{O}_{2}$ atoms resultant experience faster reduction and reoxidation by gaseous $\mathrm{O}_{2}[179,180]$. Furthermore, the redox properties of $\mathrm{V}_{2} \mathrm{O}_{5}$ are modified by the incorporation of $\mathrm{TiO}_{2}$, leading to an electronic interaction between $\mathrm{TiO}_{2}$ and $\mathrm{V}_{2} \mathrm{O}_{5}$. There are some reports discussing the fact that the addition of molybdenum oxides $\left(\mathrm{MoO}_{2}\right)$ species to $\mathrm{V}_{2} \mathrm{O}_{5} / \mathrm{TiO}_{2}$ heterogeneous catalyst causes dramatic changes in the 1,2-dichlorobenzene oxidation, most importantly, by improving the catalytic activity $[181,182]$.

3.2.3. $\mathrm{MnO} / \mathrm{TiO}_{2}$ Heterogeneous Catalyst. Manganese oxides $(\mathrm{MnO})$, containing several types of labile oxygen, which are necessary to complete the catalytic cycle, have relatively high activity, but their optimal temperature (above $150^{\circ} \mathrm{C}$ ) is still high [183-185]. For example, the activity and selectivity of pure $\mathrm{MnO}$ on $\mathrm{NO}$ conversion reached $90 \%$ selectivity [184]. To enhance the catalytic activity, $\mathrm{MnO}$ are usually supported on $\mathrm{TiO}_{2}$ as a carrier. In this regard, the dispersion of the $\mathrm{MnO}$ towards $\mathrm{TiO}_{2}$ support had an important influence on the reaction, since crystalline $\mathrm{MnO}$ contributed little to activity $[186,187]$. This, in turn, possesses profound surface acid-base properties and provides high surface area, strong mechanical strength, and high thermal stability [188].

Existing research on supported $\mathrm{MnO}$ to $\mathrm{TiO}_{2}$ heterogeneous catalyst for $\mathrm{NO}$ oxidation demonstrated high catalytic activity [189-192]. For example, a series of $\mathrm{MnO} / \mathrm{TiO}_{2}$ heterogeneous catalyst prepared by the deposition-precipitation method and the sample with the Mn/Ti ratio of 0.3 showed a superior activity for $\mathrm{NO}$ catalytic oxidation to $\mathrm{NO}_{2}$ [188]. Therefore, the maximum NO conversion over the $\mathrm{MnO} / \mathrm{TiO}_{2}$ heterogeneous catalyst could reach $89 \%$ in $250^{\circ} \mathrm{C}$ [189]. Indeed, $\mathrm{MnO} / \mathrm{TiO}_{2}$ heterogeneous catalyst showed an interesting development as a highly active heterogeneous catalyst with low pollution for the low temperature NO conversion process [190]. Meanwhile, some studies reported on $\mathrm{MnO} / \mathrm{TiO}_{2}$ heterogeneous catalyst being prepared by sol-gel, impregnation, and coprecipitation methods for lowtemperature selective catalytic reduction of $\mathrm{NO}$ with $\mathrm{NH}_{3}$ $[191,192]$. Strong interaction, high concentration of hydroxyl groups, large surface area, and high concentration of amorphous Mn on the surface might be the main reasons for the excellent performance of the catalysts [191].

It was documented that the crystal phase of the $\mathrm{TiO}_{2}$ influences catalysts' activity [193-197]. Therefore, some studies on the effect of the crystalline phase of $\mathrm{TiO}_{2}$ towards the catalytic performance of $\mathrm{MnO} / \mathrm{TiO}_{2}$ heterogeneous catalyst were carried out in [194], and it was discovered that compared to anatase and rutile anatase+rutile resulted in better dispersion of $\mathrm{MnO}$ on the support surface, suppressed the agglomeration of catalyst particles, and produced more $\mathrm{Mn}_{2} \mathrm{O}_{3}$, which is more active for the oxidation of NO [195, 196]. In addition, anatase+rutile enhanced the reduction of $\mathrm{MnO}$, especially for $\mathrm{Mn}_{2} \mathrm{O}_{3}$, and the formation of easily desorbed $\mathrm{O}^{2-}$ generated from the $\mathrm{Mn}^{3+}-\mathrm{O}$ bond [197].

3.2.4. $\mathrm{RuO} \mathrm{O}_{2} / \mathrm{TiO}_{2}$ Heterogeneous Catalyst. Ruthenium oxide supported $\mathrm{TiO}_{2}\left(\mathrm{RuO}_{2} / \mathrm{TiO}_{2}\right)$ heterogeneous catalyst found an attraction in the oxidation process $[198,199]$. Generally, $\mathrm{RuO}_{2} / \mathrm{TiO}_{2}$ heterogeneous catalysts are prepared by the impregnation of Ru salt, followed by calcination, with limited control on the properties of the $\mathrm{RuO}_{2}$ species formation [199]. Furthermore, a recent development of green method to prepare calibrated $\mathrm{RuO}_{2}$ nanoparticles has been developed and analyzed. It is expected that, for this kind of preparation method, the $\mathrm{RuO}_{2} / \mathrm{TiO}_{2}$ heterogeneous catalyst exhibits outstanding oxidation activity [200].

3.3. $\mathrm{TiO}_{2}$ : As Support in Bimetallic Heterogeneous Catalysis. In this area, the availability, affordability, and lack of toxicity of $\mathrm{TiO}_{2}$ as a robust solid with outstanding photochemical stability make it an attractive support for the bimetallic heterogeneous catalyst. $\mathrm{TiO}_{2}$ is used for its well-known ability to interact with bimetallic through the formation of $\mathrm{Ti}^{3+}$ ions. Generally, any electronic conductivity of $\mathrm{TiO}_{2}$ is due to the presence of $\mathrm{Ti}^{3+}$ ions. There are two ways to create $\mathrm{Ti}^{3+}$ ions in the $\mathrm{TiO}_{2}$ structure. The formation of $\mathrm{Ti}^{3+}$ ions either through the $\mathrm{O}_{2}$ vacancy creation or through shear planes 
by introducing appropriate donor dopants. It is well known that strong bimetallic support interaction occurred as the bimetallic catalyst was reduced by $\mathrm{H}_{2}$. The $\mathrm{H}_{2}$ reduction over $\mathrm{TiO}_{2}$ supported bimetallic catalyst generates $\mathrm{O}_{2}$ vacancies in the form of coordinate unsaturated cations in the vicinity of active bimetallic, which in the end results in changes in the catalytic activity and stability.

3.3.1. PdNi/TiO 2 Heterogeneous Catalyst. Spherical $\mathrm{TiO}_{2}$ nanoparticles were used to synthesize the PdNi-supported $\mathrm{TiO}_{2}$ electrocatalyst for methanol oxidation [201]. It was found that the electrocatalytic activity of $\mathrm{PdNi} / \mathrm{TiO}_{2}$ catalyst is much more promising, better than the antipoisoning capability, and comparatively favorable as compared to commercial $31 \mathrm{PtRu}$-supported carbon [201]. The methanol oxidation mechanism of the $\mathrm{PdNi} / \mathrm{TiO}_{2}$ heterogeneous catalyst mainly results from the high catalytic activity of the hybrid system without UV light illumination. Therefore, $\mathrm{PdNi} / \mathrm{TiO}_{2}$ catalyst might become a promising candidate for a direct-methanol fuel cell.

3.3.2. $\mathrm{AuCu} / \mathrm{TiO}_{2}$ Heterogeneous Catalyst. The $\mathrm{AuCu} / \mathrm{TiO}_{2}$ heterogeneous catalyst was studied for several other reactions, including water, gas shift, and total oxidation of methane, ethane, propane, and epoxidation of propane. The incorporation of $\mathrm{Au}$ into $\mathrm{Cu}$ complements each other in terms of electronic properties, $\mathrm{O}_{2}$ mobility, and surface stability $[202,203]$. The interaction of $\mathrm{Au}$ and $\mathrm{Cu}$ in $\mathrm{AuCu} / \mathrm{TiO}_{2}$ bimetallic heterogeneous catalyst was analyzed for methanol oxidation, and it was found that the catalytic activity and selectivity of the bimetallic heterogeneous catalyst system are greater than the one with the monolithic catalyst [202].

3.3.3. $\mathrm{CoMn} / \mathrm{TiO}_{2}$ Heterogeneous Catalyst. A series of $\mathrm{CoMn} / \mathrm{TiO}_{2}$ heterogeneous catalysts, with a composition range of $2-12 \mathrm{wt} \%$ containing $25 \%$ Co and $75 \% \mathrm{Mn}$, have been prepared by the coimpregnation method [204-206]. The produced $\mathrm{CoMn} / \mathrm{TiO}_{2}$ heterogeneous catalyst was tested in Fischer-Tropsch synthesis for the production of $\mathrm{C} 2-\mathrm{C} 4$ olefins [205], and it was discovered that the heterogeneous catalyst containing $8 \mathrm{wt} \%(\mathrm{CoMn}) / \mathrm{TiO}_{2}$ is the optimal formulation for the production of $\mathrm{C} 2-\mathrm{C} 4$ olefins. It should also be pointed out that the operating conditions, such as the $\mathrm{H}_{2} / \mathrm{CO}$ molar feed ratio, temperature, Gas Hourly Space Velocity, and total reaction pressure affect the heterogeneous catalytic performance of an optimal catalyst [204].

\section{Applications of $\mathrm{TiO}_{2}$ Supported Heterogeneous Catalysis}

4.1. Environmental Security: Photocatalysis. Recently, $\mathrm{TiO}_{2}{ }^{-}$ supported semiconductor is extensively used to mineralize toxic and nonbiodegradable environmental pollutants due to its high effectiveness, long-term photostability, and nontoxicity $[66,76]$. This is also attributed to the limitation of most semiconductors, such as low quantum efficiency, small specific surface area, and low adsorption ability. This in turn limits the efficiency of the photocatalyst. On the other hand, both costly and difficult separation of reaction media and the inadequacy for continuous processing are some of the restrictive factors [110]. As a result, a number of studies have focused on the immobilization of semiconductor materials onto porous $\mathrm{TiO}_{2}$ nanoparticles [156]. This is believed to not only promote photocatalytic reactions by offering more active sites but also allow the recycling and reuse of semiconductor as a heterogeneous catalyst. Some data also reported that porous $\mathrm{TiO}_{2}$ nanoparticle has shown some advantages in the preparation of highly supported catalysts due to its special physicochemical properties, including high adsorption capabilities [66].

Indeed, it is well known that $\mathrm{TiO}_{2}$, with its crystallographic forms, small particle size, and highly porous structure, greatly influence the photocatalytic performance of composite materials [76]. Among metal oxides suitable for photocatalytic processes, $\mathrm{TiO}_{2}$ is the most widely used, due to both its high photocatalytic activity and its chemi$\mathrm{cal} /$ photocorrosion stability in the reaction conditions. $\mathrm{TiO}_{2}$ has increased the photoactivities, due to the photoinduced electron-hole pairs on its surface that can be harvested to increase electron transfer and chemical reactivity. The semiconductor nature of $\mathrm{TiO}_{2}$ has made it possible for the utilization of UV-Visible radiation to harvest the conduction band electrons that are subsequently used to reduce metallic ions onto $\mathrm{TiO}_{2}$ 's surface $[66,156]$. Therefore, the immobilization of semiconductor on a $\mathrm{TiO}_{2}$ nanoparticle can exhibit a higher photodecomposition of organic and inorganic pollutant compared to nonsupported semiconductors [110].

4.2. Chemical Reaction/Conversion. As a versatile metal/metal oxide supported $\mathrm{TiO}_{2}$ heterogeneous catalyst, it is broadly studied in a variety of mild oxidation reactions, such as ethane to acetic acid, ethanol to acetaldehyde, and oxidative dehydrogenation of propane to propylene $[8,9,16]$. For example, various $\mathrm{TiO}_{2}$ supported catalysts, including $\mathrm{Au} / \mathrm{TiO}_{2}, \mathrm{Pd} / \mathrm{TiO}_{2}, \mathrm{Co} / \mathrm{TiO}_{2}$, and $\mathrm{Pt} / \mathrm{TiO}_{2}$, have recently been developed for frequent industrial applications, including the hydrosulfurization of hydrocarbon oils, the epoxidation of propane, and the selective catalytic reduction of NO [36, 43, 46-48]. However, since these aforementioned reactions are powerfully exothermic, it is important to avoid the hot spots that are responsible for structural damages and early deactivation of heterogeneous catalyst [53, 56-59]. Generally, the presence of hot spot leading from products productions included $\mathrm{CO}_{2}$, especially in oxidation reaction [60]. As an alternative, recent studies focused on the $3 \mathrm{D}$ structure of metal/metal oxide supported $\mathrm{TiO}_{2}$ with an open structure [63]. The open structure of metal/metal oxide supported $\mathrm{TiO}_{2}$ catalyst favor efficient heat and mass transfers between the gaseous reactants, the catalytic active phase, and the wall of the chemical reactors.

Furthermore, metal oxide supported $\mathrm{TiO}_{2}$ heterogeneous catalysts are commonly used in several industrial important reactions, including selective reduction of $\mathrm{NO}$ by $\mathrm{NH}_{3}[109$, 121]. It should be pointed out that metal oxide supported $\mathrm{TiO}_{2}$ heterogeneous catalyst demonstrated excellent performance in slurry reactions $[123,128]$. Indeed, $\mathrm{TiO}_{2}$, utilized as support 

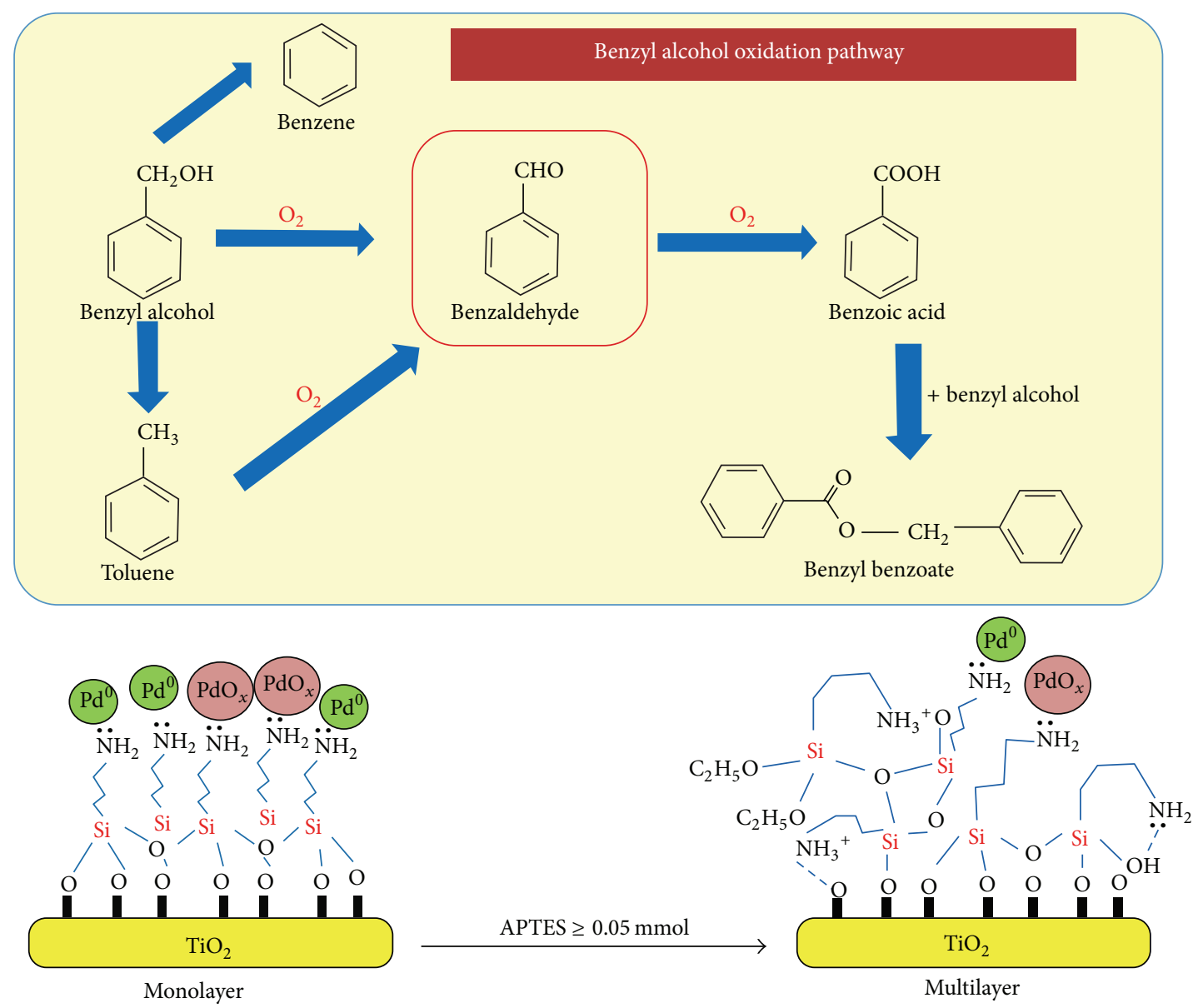

FIGURE 6: Surface functionalized $\mathrm{TiO}_{2}$ supported Pd catalysts for solvent-free selective oxidation of benzyl alcohol [207].

for metal oxide, attracts considerable interest due to its favorable properties of low pressure drop, thermal shock resistance, chemical durability, low manufacturing cost, and high structural strengths [134-136, 160].

4.2.1. Small Molecules Transformation. Recently, heterogeneous catalyst supported $\mathrm{TiO}_{2}$ for small molecules transformation has received considerable attention because of its simplicity and the advantages, over most other methods of preparing highly pure mixed oxides and a variety of other materials [13]. This included sulfides and phosphates, which are obtained under very similar experimental conditions. The preparation of metal particles with $\mathrm{TiO}_{2}$ supported catalyst is commonly applied because of its mild reducing performance which has a chelating effect, which avoids agglomeration of particles during preparation [57]. The synthesis of monoor polymetal particles of $\mathrm{Co}, \mathrm{Ni}, \mathrm{Cu}$, and noble metals in submicrometer and -nanometer size range has been reported and the materials obtained by catalyzed supported of $\mathrm{TiO}_{2}$ show homogenous phase composition, narrow particle distribution, and high specific surface area [203]. For example, polyol-mediated preparation of nanoscale oxides can carry out by dissolving a suitable metal precursor (acetate, alcoholate, and halogenide) in diethylene glycol or other polyalcohol with assisted of heterogeneous catalyst supported $\mathrm{TiO}_{2}$. During this step, the surface of growing particles will be immediately complexed by $\mathrm{TiO}_{2}$ as a catalyst support material, which limit grain growth [49].

Heterogeneous catalyst supported $\mathrm{TiO}_{2}$ also applied for the nitrate to nitrite reduction with bimetallic catalyst. It is expected that $\mathrm{H}_{2}$ molecules produced through the reaction and adsorbed on noble metal subsequently reduces nitrite to harmless $\mathrm{N}_{2}$ gas [207]. A wide range of metal pairs included $\mathrm{Au}-\mathrm{Pd}, \mathrm{Sn}-\mathrm{Pd}, \mathrm{Ni}-\mathrm{Rh}, \mathrm{Rh}-\mathrm{Cu}$, and $\mathrm{Pd}-\mathrm{Cu}$ supported on $\mathrm{TiO}_{2}$ were extensively studied to maximize the efficiency of nitrate reduction to $\mathrm{N}_{2}$ gas. In advances, some studies focus on the effect of $\mathrm{pH}$ and zwitterionic buffer on catalytic nitrate reduction by $\mathrm{Cu}-\mathrm{Pd}$ supported $\mathrm{TiO}_{2}$ and found that the nitrate reduction decreased from $100 \%$ to $72 \%$ as suspension of $\mathrm{pH}$ increased from 6 to 10 of which range was kept by zwitterionic buffers [207] (Figure 6).

4.2.2. Organic Synthesis. It also revealed that Pd catalyst supported $\mathrm{TiO}_{2}$ could be functionalized with various amounts of 3-aminopropyltriethoxysilane via a post synthesis grafting method combined with electroless deposition of Pd [108]. The supported catalyst system gave promising catalytic properties in the solvent-free selective oxidative of benzyl alcohol. It 


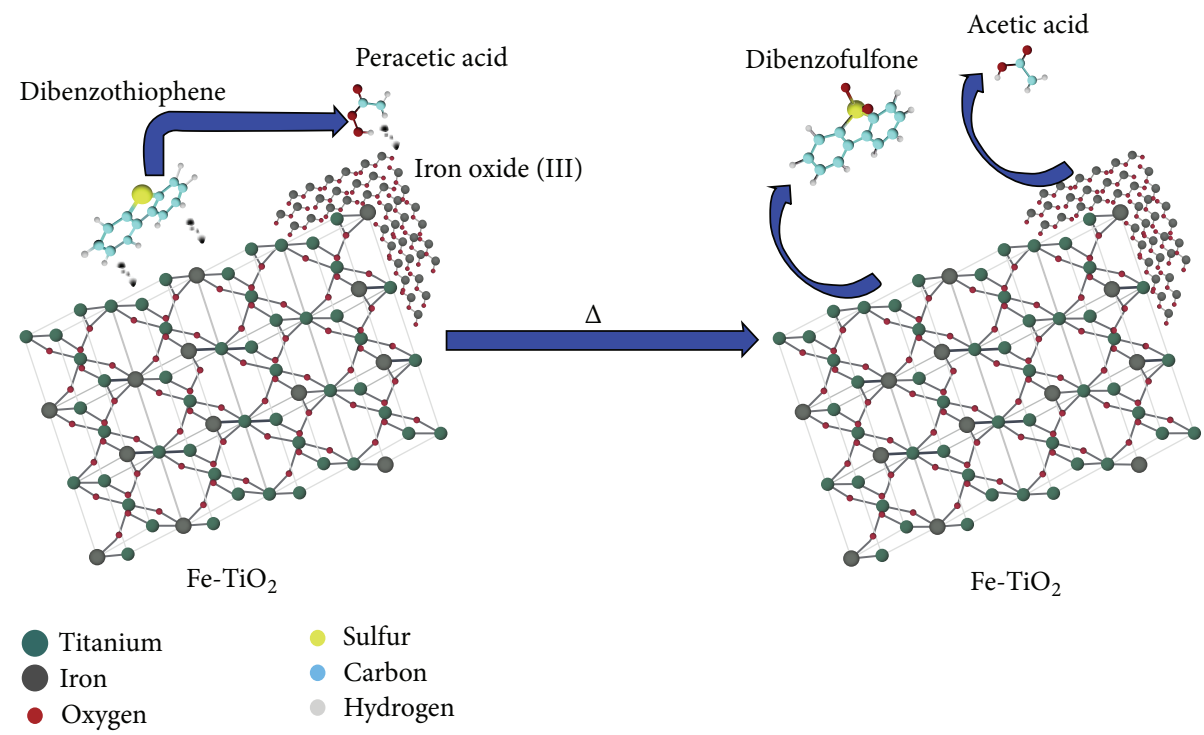

FIGURE 7: Oxidative removal of dibenzothiophene in a biphasic system using sol-gel Fe/ $\mathrm{TiO}_{2}$ catalysts and $\mathrm{H}_{2} \mathrm{O}_{2}$ promoted with acetic acid [208].

correlated well with the highest amount of Pd distribution (with particle size of $3.4 \mathrm{~nm}$ ) with the $1 \%$ of Pd-supported $\mathrm{TiO}_{2}$. Increasing of surface basicity via the hydrolysis of $\mathrm{NH}_{2}$ suggested enhancing the dehydrogenation of benzyl alcohol and, as a consequence, the selectivity towards benzaldehyde [109-111]. In addition, the presence of $\mathrm{TiO}_{2}$ support gave high catalytic activity in benzyl alcohol oxidation, emphasizing that the reduction of $\mathrm{PdOx}$ species by the adsorbed benzyl alcohol is an essential step to form highly active metallic PdO sites [112].

4.2.3. Organic Reactions. Another important application of heterogeneous catalyst supported $\mathrm{TiO}_{2}$ derived from the Fisher-Tropsch synthesis, which can convert various carbon sources (coal, natural gas, and biomass) into long chain hydrocarbon via syngas [103]. It is a promising way to produce environmentally benign fuels with no sulfur and nitrogen compounds [116]. In this case, certain transition metals supported with $\mathrm{TiO}_{2}$ have frequently applied as catalyst. Among them, $\mathrm{Co} / \mathrm{TiO}_{2}$ is considered as the preferred catalyst due to its high selectivity for long chain linear paraffin, high resistance toward deactivation by water, and low activity for the competitive water gas shift reaction [25]. Several studies indicated that activity of Co catalyst depended on the number of exposed metal sites [90, 93, 95, 96]. Therefore, the $\mathrm{Co} / \mathrm{TiO}_{2}$ catalyst system may increase the dispersion of active Co metal species. Meanwhile, $\mathrm{TiO}_{2}$ is suitable for the practical application due to the low cost, safety, and the chemical stability. Furthermore, it is reported that the strength of Co support interaction of $\mathrm{Co} / \mathrm{TiO}_{2}$ was in the middle of those on $\mathrm{Co} / \mathrm{SiO}_{2}$ and $\mathrm{Co} / \mathrm{Al}_{2} \mathrm{O}_{3}[99,100]$. It found that the activity of the $\mathrm{Co} / \mathrm{TiO}_{2}$ catalyst for FischerTropsch synthesis largely depended on the crystal phase of $\mathrm{TiO}_{2}$ support, the reduction degree of $\mathrm{Co}$, and the surface area of Co metal. Rutile $\mathrm{TiO}_{2}$ gives more optimum reduction degree of Co with almost $60 \%$ as compared to the anatase [204, 205].

Another interesting application of $\mathrm{TiO}_{2}$ supported catalyst is the use of $\mathrm{Fe} / \mathrm{TiO}_{2}$ in petroleum refining industries. Several routes can apply the $\mathrm{Fe} / \mathrm{TiO}_{2}$ catalyst system including oxidation, adsorption, hydrodesulfurization, oxidative desulfurization, and biodesulfurization for organosulfur compounds removal from crude oil and refined petroleum products $[2,59]$. This is due to the surface of $\mathrm{Fe} / \mathrm{TiO}_{2}$ catalyst possess electron-hole pairs and free $\mathrm{OH}$ radicals [92]. Highly reactive $\mathrm{OH}$ radicals can also be formed by the reaction of the hole with $\mathrm{OH}$-, which are able to generate oxidizing radicals in the presence of peroxides and may perform the oxidative desulfurization better due to recombination reactions occurring via free radical mechanisms [204]. Rather than that, the hydrophilic-hydrophobic character of $\mathrm{Fe} / \mathrm{TiO}_{2}$ facilitate dibenzothiophene oxidation as a phase transfer catalyst. The coordination of acetic acid and peroxyacetic acid with $\mathrm{Fe}^{3+}$ and $\mathrm{Ti}^{4+}$ present at the $\mathrm{Fe} / \mathrm{TiO}_{2}$ surface which in turn perform a superoxides its surface [208] (Figure 7).

4.3. Electrochemical Applications. $\mathrm{TiO}_{2}$ is an interesting material to evaluate as a heterogeneous catalyst support for electrochemical applications, not only because of its high stability cathode potentials in acidic and hydrous environment $[19,34]$, but also because of the recent reports introducing Ti-containing material into the electrodes [118, 142]. Substoichiometric $\mathrm{Ti}_{n} \mathrm{O}_{2 n-2}$ has been studied and performs well as a catalyst support in cathodes [90, 126]. It has been reported that once metals are deposited on $\mathrm{TiO}_{2}$, it indicates an increased electrochemically active area [139, 142]. The incorporation of $\mathrm{TiO}_{2}$ into the cathode indicated the improved methanol tolerance and its proton conductor properties [111]. 


\section{Conclusion and Suggestions}

$\mathrm{TiO}_{2}$ is a reducible metal oxide and strongly reacts with noble metals compared to other metal oxides. For this reason, $\mathrm{TiO}_{2}$ has attracted much attention for application as heterogeneous catalyst support in many reactions. It is inferred that catalyst support on $\mathrm{TiO}_{2}$ with different structures might exhibit different physicochemical properties and catalytic activities. Generally, pure $\mathrm{TiO}_{2}$ possesses abysmal electronic conductivity. It is proposed that substoichiometric $\mathrm{TiO}_{2}$ is prepared in order to improve its conductivity. Although the electronic conductivity improved by utilizing $\mathrm{TiO}_{2}$ as a heterogeneous catalyst support, the stability was compromised after extensive polarization at high oxygen electrode potentials. Therefore, another method that could improve electronic conductivity is to dope $\mathrm{TiO}_{2}$ with $n$-type dopants, including niobium $(\mathrm{Nb})$ or tantalum $(\mathrm{Ta})$. It has been reported in literature that $\mathrm{TiO}_{2}$, with a/an rutile/anatase structure doped $\mathrm{Nb}$, had a significantly greater electronic conductivity compared to the native $\mathrm{TiO}_{2}$. The presence of $\mathrm{Ti}^{3+}$ species was observed, which was induced by the partial replacement of $\mathrm{Ti}^{4+}$ by $\mathrm{Nb}^{5+}$. Therefore, in all cases, $\mathrm{Nb}$ $\mathrm{TiO}_{2}$ is both electrochemically and thermally stable, which can further promote explorations for heterogeneous catalyst support.

\section{Conflict of Interests}

The authors declare that all the written materials related to the text, tables, and figures for paper of "Titanium Dioxide as a Catalyst Support in Heterogeneous Catalysis" do not have any conflict of interests concerning the validity of research and financial gain.

\section{Acknowledgments}

This work is financially supported by University Malaya Research Grant UMRG RP022-2012E and Fundamental Research Grant Scheme (FRGS: FP049-2013B) by Universiti Malaya and Ministry of High Education (MOE), Malaysia.

\section{References}

[1] F. Adam, J. N. Appaturi, and A. Iqbal, "The utilization of rice husk silica as a catalyst: review and recent progress," Catalysis Today, vol. 190, no. 1, pp. 2-14, 2012.

[2] C. Pellecchia, M. Mazzeo, and D. Pappalardo, "Isotactic-specific polymerization of propene with an iron-based catalyst: polymer end groups and regiochemistry of propagation," Macromolecular Rapid Communications, vol. 19, no. 12, pp. 651-655, 1998.

[3] K.-H. Lee, N.-S. Noh, D.-H. Shin, and Y. Seo, "Comparison of plastic types for catalytic degradation of waste plastics into liquid product with spent FCC catalyst," Polymer Degradation and Stability, vol. 78, no. 3, pp. 539-544, 2002.

[4] D. J. Pollard and J. M. Woodley, "Biocatalysis for pharmaceutical intermediates: the future is now," Trends in Biotechnology, vol. 25, no. 2, pp. 66-73, 2007.

[5] A. Daugherty, J. L. Dunn, D. L. Rateri, and J. W. Heinecke, "Myeloperoxidase, a catalyst for lipoprotein oxidation, is expressed in human atherosclerotic lesions," Journal of Clinical Investigation, vol. 94, no. 1, pp. 437-444, 1994.

[6] M. W. Kanan and D. G. Nocera, "In situ formation of an oxygenevolving catalyst in neutral water containing phosphate and Co2+," Science, vol. 321, no. 5892, pp. 1072-1075, 2008.

[7] L. Hu, X. Yang, and S. Dang, "An easily recyclable Co/SBA15 catalyst: Heterogeneous activation of peroxymonosulfate for the degradation of phenol in water," Applied Catalysis B: Environmental, vol. 102, no. 1-2, pp. 19-26, 2011.

[8] Y. Kazuya and M. Noritaka, "Supported ruthenium catalyst for the heterogeneous oxidation of alcohols with molecular oxygen," Angewandte Chemie International Edition, vol. 41, no. 23, pp. 4538-4542, 2002.

[9] K. Mori, T. Hara, T. Mizugaki, K. Ebitani, and K. Kaneda, "Hydroxyapatite-supported palladium nanoclusters: a highly active heterogeneous catalyst for selective oxidation of alcohols by use of molecular oxygen," Journal of the American Chemical Society, vol. 126, no. 34, pp. 10657-10666, 2004.

[10] K. T. Wan and M. E. Davis, "Design and synthesis of a heterogeneous asymmetric catalyst," Nature, vol. 370, no. 6489, pp. 449-450, 1994.

[11] N. Shibasaki-Kitakawa, H. Honda, H. Kuribayashi, T. Toda, T. Fukumura, and T. Yonemoto, "Biodiesel production using anionic ion-exchange resin as heterogeneous catalyst," Bioresource Technology, vol. 98, no. 2, pp. 416-421, 2007.

[12] R. Liu, R. Jin, J. An, Q. Zhao, T. Cheng, and G. Liu, "Hollowshell-structured nanospheres: a recoverable heterogeneous catalyst for rhodium-catalyzed tandem reduction/lactonization of ethyl 2-acylarylcarboxylates to chiral phthalides," ChemistryAn Asian Journal, vol. 9, no. 5, pp. 1388-1394, 2014.

[13] Y. Leng, J. Liu, P. Jiang, and J. Wang, "Organometallicpolyoxometalate hybrid based on V-Schiff base and phosphovanadomolybdate as a highly effective heterogenous catalyst for hydroxylation of benzene," Chemical Engineering Journal, vol. 239, pp. 1-7, 2014.

[14] P. Cong, R. D. Doolen, Q. Fan et al., "High-throughput synthesis and screening of combinatorial heterogeneous catalyst libraries," Angewandte Chemie, vol. 38, no. 4, pp. 484-488, 1999.

[15] B. Uysal and B. S. Oksal, "New heterogeneous $\mathrm{B}(\mathrm{OEt})_{3}$ MCM-41 catalyst for preparation of $\alpha, \beta$-unsaturated alcohols," Research on Chemical Intermediates, 2013.

[16] K. Yamaguchi, C. Yoshida, S. Uchida, and N. Mizuno, "Peroxotungstate immobilized on ionic liquid-modified silica as a heterogeneous epoxidation catalyst with hydrogen peroxide," Journal of the American Chemical Society, vol. 127, no. 2, pp. 530$531,2005$.

[17] J. M. Planeix, N. Coustel, B. Coq et al., "Application of carbon nanotubes as supports in heterogeneous catalysis," Journal American Chemical Society, vol. 116, no. 17, pp. 7935-7936, 1994.

[18] P. D. Kent, J. E. Mondloch, and R. G. Finke, "A four-step mechanism for the formation of supported-nanoparticle heterogenous catalysts in contact with solution: the conversion of $\operatorname{Ir}(1,5-\mathrm{COD}) \mathrm{Cl} / \gamma-\mathrm{Al}_{2} \mathrm{O}_{3}$ to $\operatorname{Ir}(0) \sim 170 / \gamma-\mathrm{Al}_{2} \mathrm{O}_{3}$, Journal of the American Chemical Society, vol. 136, no. 5, pp. 1930-1941, 2014.

[19] A. Dobrzeniecka and P. J. Kulesza, "Electrocatalytic activity toward oxygen reduction of $\mathrm{RuSxN}$ y catalysts supported on different nanostructured carbon carriers," ECS Journal of Solid State Science and Technology, vol. 2, no. 12, pp. M61-M66, 2013.

[20] D. Astruc, F. Lu, and J. R. Aranzaes, "Nanoparticles as recyclable catalysts: the frontier between homogeneous and heterogeneous catalysis," Angewandte Chemie-International Edition, vol. 44, no. 48, pp. 7852-7872, 2005. 
[21] C. M. Crudden, M. Sateesh, and R. Lewis, "Mercaptopropylmodified mesoporous silica: a remarkable support for the preparation of a reusable, heterogeneous palladium catalyst for coupling reactions," Journal of the American Chemical Society, vol. 127, no. 28, pp. 10045-10050, 2005.

[22] B. E. Solsona, J. K. Edwards, P. Landon et al., "Direct synthesis of hydrogen peroxide from $\mathrm{H}_{2}$ and $\mathrm{O}_{2}$ using $\mathrm{Al}_{2} \mathrm{O}_{3}$ supported Au-Pd catalysts," Chemistry of Materials, vol.18, no. 11, pp. 26892695, 2006.

[23] A. Corma, M. Iglesias, C. del Pino, and F. Sánchez, "New rhodium complexes anchored on modified USY zeolites. A remarkable effect of the support on the enantioselectivity of catalytic hydrogenation of prochiral alkenes," Journal of the Chemical Society-Series Chemical Communications, no. 18, pp. 1253-1255, 1991.

[24] B. Kraeutler and A. J. Bard, "Heterogeneous photocatalytic preparation of supported catalysts. Photodeposition of platinum on $\mathrm{TiO} 2$ powder and other substrates," Journal of the American Chemical Society, vol. 100, no. 13, pp. 4317-4318, 1978.

[25] T. O. Eschemann, J. H. Bitter, and K. P. de Jong, "Effects of loading and synthesis method of titania-supported cobalt catalysts for Fischer-Tropsch synthesis," Catalysis Today, vol. 228, pp. 89-95, 2014.

[26] G. K. Mor, K. Shankar, M. Paulose, O. K. Varghese, and C. A. Grimes, "Use of highly-ordered $\mathrm{TiO}_{2}$ nanotube arrays in dyesensitized solar cells," Nano Letters, vol. 6, no. 2, pp. 215-218, 2006.

[27] A. D’Agata, S. Fasulo, L. J. Dallas et al., "Enhanced toxicity of "bulk" titanium dioxide compared to "fresh" and "aged" nano$\mathrm{TiO}_{2}$ in marine mussels (Mytilus galloprovincialis)," Nanotoxicology, vol. 8, no. 5, pp. 549-558, 2014.

[28] Y.-G. Guo, Y.-S. Hu, W. Sigle, and J. Maier, "Superior electrode performance of nanostructured mesoporous $\mathrm{TiO}_{2}$ (Anatase) through efficient hierarchical mixed conducting networks," Advanced Materials, vol. 19, no. 16, pp. 2087-2091, 2007.

[29] J. Xu, K. Li, W. Shi, R. Li, and T. Peng, "Rice-like brookite titania as an efficient scattering layer for nanosized anatase titania filmbased dye-sensitized solar cells," Journal of Power Sources, vol. 260, pp. 233-242, 2014.

[30] M.-M. Chen, X. Sun, Z.-J. Qiao, Q.-Q. Ma, and C.-Y. Wang, "Anatase- $\mathrm{TiO}_{2}$ nanocoating of $\mathrm{Li}_{4} \mathrm{Ti}_{5} \mathrm{O}_{12}$ nanorod anode for lithium-ion batteries," Journal of Alloys and Compounds, vol. 601, pp. 38-42, 2014.

[31] M. Fujimoto, H. Koyama, M. Konagai et al., “ $\mathrm{TiO}_{2}$ anatase nanolayer on TiN thin film exhibiting high-speed bipolar resistive switching," Applied Physics Letters, vol. 89, no. 22, Article ID 223509, 2006.

[32] D. Grosso, G. J. D. A. A. Soler-Illia, E. L. Crepaldi et al., "Highly Porous $\mathrm{TiO}_{2}$ Anatase Optical Thin Films with Cubic Mesostructure Stabilized at $700^{\circ} \mathrm{C}$," Chemistry of Materials, vol. 15, no. 24, pp. 4562-4570, 2003.

[33] D. Ramimoghadam, S. Bagheri, and S. B. Abd Hamid, "Biotemplated synthesis of anatase titanium dioxide nanoparticles via lignocellulosic waste material," BioMed Research International, vol. 2014, Article ID 205636, 7 pages, 2014.

[34] J. Wang, J. Polleux, J. Lim, and B. Dunn, "Pseudocapacitive contributions to electrochemical energy storage in $\mathrm{TiO}_{2}$ (Anatase) nanoparticles," Journal of Physical Chemistry C, vol. 111, no. 40, pp. 14925-14931, 2007.

[35] H. Kominami, J.-I. Kalo, Y. Takada et al., "Novel synthesis of microcrystalline titanium(IV) oxide having high thermal stability and ultra-high photocatalytic activity: thermal decomposition of titanium(IV) alkoxide in organic solvents," Catalysis Letters, vol. 46, no. 1-2, pp. 235-240, 1997.

[36] S. Bagheri, K. Shameli, and S. B. Abd Hamid, "Synthesis and characterization of anatase titanium dioxide nanoparticles using egg white solution via Sol-Gel method," Journal of Chemistry, vol. 2013, Article ID 848205, 5 pages, 2013.

[37] R. Palcheva, L. Dimitrov, G. Tyuliev, A. Spojakina, and K. Jiratova, " $\mathrm{TiO}_{2}$ nanotubes supported $\mathrm{NiW}$ hydrodesulphurization catalysts: characterization and activity," Applied Surface Science, vol. 265, pp. 309-316, 2013.

[38] G. Liang, L. He, H. Cheng et al., "The hydrogenation/dehydrogenation activity of supported $\mathrm{Ni}$ catalysts and their effect on hexitols selectivity in hydrolytic hydrogenation of cellulose," Journal of Catalysis, vol. 309, pp. 468-476, 2014.

[39] Q. Luo, M. Beller, and H. Jiao, "Formic acid dehydrogenation on surfaces-a review of computational aspect," Journal of Theoretical and Computational Chemistry, vol. 12, no. 7, Article ID 1330001, 2013.

[40] M. Nolan, "Modifying ceria (111) with a $\mathrm{TiO}_{2}$ nanocluster for enhanced reactivity," Journal of Chemical Physics, vol. 139, no. 18, Article ID 184710, 2013.

[41] L. Si, Z. Huang, K. Lv, D. Tang, and C. Yang, "Facile preparation of $\mathrm{Ti} 3+$ self-doped $\mathrm{TiO}_{2}$ nanosheets with dominant $\begin{array}{lll}0 & 0 & 1\end{array}$ facets using zinc powder as reductant," Journal of Alloys and Compounds, vol. 601, pp. 88-93, 2014.

[42] N. M. Julkapli, S. Bagheri, and S. B. Abd Hamid, "Recent advances in heterogeneous photocatalytic decolorization of synthetic dyes," The Scientific World Journal, vol. 2014, Article ID 692307, 25 pages, 2014.

[43] X.-L. Sui, Z.-B. Wang, M. Yang, L. Huo, D.-M. Gu, and G.-P. Yin, "Investigation on $\mathrm{C}-\mathrm{TiO}_{2}$ nanotubes composite as Pt catalyst support for methanol electrooxidation," Journal of Power Sources, vol. 255, pp. 43-51, 2014.

[44] G. R. Bamwenda, S. Tsubota, T. Nakamura, and M. Haruta, "The influence of the preparation methods on the catalytic activity of platinum and gold supported on $\mathrm{TiO}_{2}$ for $\mathrm{CO}$ oxidation," Catalysis Letters, vol. 44, no. 1-2, pp. 83-87, 1997.

[45] S. J. Tauster, S. C. Fung, R. T. K. Baker, and J. A. Horsley, "Strong interactions in supported-metal catalysts," Science, vol. 211, article 4487, 1981.

[46] T. S. Kim, J. D. Stiehl, C. T. Reeves, R. J. Meyer, and C. B. Mullins, "Cryogenic $\mathrm{CO}$ oxidation on $\mathrm{TiO}_{2}$-supported gold nanoclusters precovered with atomic oxygen," Journal of the American Chemical Society, vol. 125, no. 8, pp. 2018-2019, 2003.

[47] L. Lietti, P. Forzatti, and F. Bregani, "Steady-state and transient reactivity study of $\mathrm{TiO}_{2}$-supported $\mathrm{V}_{2} \mathrm{O}_{5}-\mathrm{WO}_{3}$ De-NOx catalysts: relevance of the vanadium-tungsten interaction on the catalytic activity," Industrial and Engineering Chemistry Research, vol. 35, no. 11, pp. 3884-3892, 1996.

[48] S. D. Lin, M. Bollinger, and M. A. Vannice, "Low temperature $\mathrm{CO}$ oxidation over $\mathrm{Au} / \mathrm{TiO}_{2}$ and $\mathrm{Au} / \mathrm{SiO}_{2}$ catalysts," Catalysis Letters, vol. 17, no. 3-4, pp. 245-262, 1993.

[49] J. M. Gallardo Amores, V. Sanchez Escribano, and G. Busca, "Anatase crystal growth and phase transformation to rutile in high-area $\mathrm{TiO}_{2}, \mathrm{MoO}_{3}-\mathrm{TiO}_{2}$ and other $\mathrm{TiO}_{2}$-supported oxide catalytic systems," Journal of Materials Chemistry, vol. 5, no. 8, pp. 1245-1249, 1995.

[50] W. Yan, S. M. Mahurin, Z. Pan, S. H. Overbury, and S. Dai, "Ultrastable Au nanocatalyst supported on surface-modified $\mathrm{TiO}_{2}$ nanocrystals," Journal of the American Chemical Society, vol. 127, no. 30, pp. 10480-10481, 2005. 
[51] X. Ren, H. Zhang, and Z. Cui, "Acetylene decomposition to helical carbon nanofibers over supported copper catalysts," Materials Research Bulletin, vol. 42, no. 12, pp. 2202-2210, 2007.

[52] K.-W. Park and K.-S. Seol, "Nb-TiO ${ }_{2}$ supported Pt cathode catalyst for polymer electrolyte membrane fuel cells," Electrochemistry Communications, vol. 9, no. 9, pp. 2256-2260, 2007.

[53] W. Yan, B. Chen, S. M. Mahurin et al., "Preparation and comparison of supported gold nanocatalysts on anatase, brookite, rutile, and $\mathrm{P} 25$ polymorphs of $\mathrm{TiO}_{2}$ for catalytic oxidation of CO," Journal of Physical Chemistry B, vol. 109, no. 21, pp. $10676-$ 10685, 2005.

[54] G. T. Went, L.-J. Leu, and A. T. Bell, "Quantitative structural analysis of dispersed vanadia species in $\mathrm{TiO}_{2}$ (Anatase)supported $\mathrm{V}_{2} \mathrm{O}_{5}$," Journal of Catalysis, vol. 134, no. 2, pp. 479491, 1992.

[55] M. S. P. Francisco and V. R. Mastelaro, "Inhibition of the anatase-rutile phase transformation with addition of $\mathrm{CeO}_{2}$ to $\mathrm{CuO}-\mathrm{TiO}_{2}$ system: raman spectroscopy, X-ray diffraction, and textural studies," Chemistry of Materials, vol. 14, no. 6, pp. 25142518, 2002.

[56] S. Carrettin, P. McMorn, P. Johnston, K. Griffin, and G. J. Hutchings, "Selective oxidation of glycerol to glyceric acid using a gold catalyst in aqueous sodium hydroxide," Chemical Communications, no. 7, pp. 696-697, 2002.

[57] F. Porta, L. Prati, M. Rossi, S. Coluccia, and G. Martra, "Metal sols as a useful tool for heterogeneous gold catalyst preparation: Reinvestigation of a liquid phase oxidation," Catalysis Today, vol. 61, no. 1, pp. 165-172, 2000.

[58] W. Fang, J. Chen, Q. Zhang, W. Deng, and Y. Wang, "Hydrotalcitesupported gold catalyst for the oxidant-free dehydrogenation of benzyl alcohol: studies on support and gold size effects," Chemistry-A European Journal, vol. 17, no. 4, pp. 1247-1256, 2011.

[59] T. M. D. Dang, T. M. H. Nguyen, and H. P. Nguyen, "The preparation of nano-gold catalyst supported on iron doped titanium oxide," Advances in Natural Sciences: Nanoscience and Nanotechnology, vol. 1, Article ID 025011, pp. 1-10, 2010.

[60] I. W. C. E. Arends and R. A. Sheldon, "Activities and stabilities of heterogeneous catalysts in selective liquid phase oxidations: recent developments," Applied Catalysis A: General, vol. 212, no. 1-2, pp. 175-187, 2001.

[61] C. Oumahi, J. Lombard, S. Casale et al., "Heterogeneous catalyst preparation in ionic liquids: titania supported gold nanoparticles," Catalysis Today, vol. 235, pp. 58-71, 2014.

[62] A. Ayati, A. Ahmadpour, F. F. Bamoharram, B. Tanhaei, M. Mänttäri, and M. Sillanpää, "A review on catalytic applications of $\mathrm{Au} / \mathrm{TiO}_{2}$ nanoparticles in the removal of water pollutant," Chemosphere, vol. 107, pp. 163-174, 2014.

[63] J. Zhou, X. Yang, Y. Wang, and W. Chen, "An efficient oxidation of cyclohexane over Au@ $\mathrm{TiO}_{2} / \mathrm{MCM}-41$ catalyst prepared by photocatalytic reduction method using molecular oxygen as oxidant," Catalysis Communications, vol. 46, pp. 228-233, 2014.

[64] M. Haruta, S. Tsubota, T. Kobayashi, H. Kageyama, M. J. Genet, and B. Delmon, "Low-Temperature Oxidation of CO over Gold Supported on $\mathrm{TiO} 2, \alpha-\mathrm{Fe}_{2} \mathrm{O}_{3}$, and $\mathrm{Co}_{3} \mathrm{O}_{4}$, Journal of Catalysis, vol. 144, no. 1, pp. 175-192, 1993.

[65] M. M. Schubert, S. Hackenberg, A. C. Van Veen, M. Muhler, V. Plzak, and J. Behm, "CO oxidation over supported gold catalysts- "Inert" and "active" support materials and their role for the oxygen supply during reaction," Journal of Catalysis, vol. 197, no. 1, pp. 113-122, 2001.
[66] M. Bowker, C. Morton, J. Kennedy et al., "Hydrogen production by photoreforming of biofuels using $\mathrm{Au}, \mathrm{Pd}$ and $\mathrm{Au}-\mathrm{Pd} / \mathrm{TiO}_{2}$ photocatalysts," Journal of Catalysis, vol. 310, no. 1, pp. 10-15, 2014.

[67] J. Guzman and B. C. Gates, "Catalysis by supported gold: correlation between catalytic activity for co oxidation and oxidation states of gold "' Journal of the American Chemical Society, vol. 126, no. 9, pp. 2672-2673, 2004.

[68] G. Li, D. I. Enache, J. Edwards, A. F. Carley, D. W. Knight, and G. J. Hutchings, "Solvent-free oxidation of benzyl alcohol with oxygen using zeolite-supported Au and Au-Pd catalysts," Catalysis Letters, vol. 110, no. 1-2, pp. 7-13, 2006.

[69] M. Hinojosa-Reyes, V. Rodríguez-González, and R. Zanella, "Gold nanoparticles supported on $\mathrm{TiO}_{2}-\mathrm{Ni}$ as catalysts for hydrogen purification via water-gas shift reaction," $R S C$ Advances, vol. 4, no. 9, pp. 4308-4316, 2014.

[70] I. X. Green, W. Tang, M. Neurock, and J. T. Yates, "Insights into catalytic oxidation at the $\mathrm{Au} / \mathrm{TiO}_{2}$ dual perimeter sites," Accounts of Chemical Research, vol. 47, no. 3, pp. 805-815, 2014.

[71] L. Li, Y. Gao, H. Li et al., "CO oxidation on $\mathrm{TiO}_{2}$ (110) supported subnanometer gold clusters: Size and shape effects," Journal of the American Chemical Society, vol. 135, no. 51, pp. 19336-19346, 2013.

[72] R. Nafria, P. Ramírez De La Piscina, N. Homs et al., "Embedding catalytic nanoparticles inside mesoporous structures with controlled porosity: Au@ $\mathrm{TiO}_{2}$," Journal of Materials Chemistry A, vol. 1, no. 45, pp. 14170-14176, 2013.

[73] A. Corma and H. Garcia, "Supported gold nanoparticles as catalysts for organic reactions," Chemical Society Reviews, vol. 37, no. 9, pp. 2096-2126, 2008.

[74] S. C. Chan and M. A. Barteau, "Preparation of highly uniform $\mathrm{Ag} / \mathrm{TiO}_{2}$ and $\mathrm{Au} / \mathrm{TiO}_{2}$ supported nanoparticle catalysts by photodeposition," Langmuir, vol. 21, no. 12, pp. 5588-5595, 2005.

[75] L. Liu, X. Gu, Y. Cao et al., "Crystal-plane effects on the catalytic properties of $\mathrm{Au} / \mathrm{TiO}_{2}$," ACS Catalysis, vol. 3, no. 12, pp. 27682775, 2013.

[76] S. Padikkaparambil, B. Narayanan, Z. Yaakob, S. Viswanathan, and S. M. Tasirin, "Au/TiO 2 reusable photocatalysts for dye degradation," International Journal of Photoenergy, vol. 2013, Article ID 752605, 10 pages, 2013.

[77] M.-Y. Xing, B.-X. Yang, H. Yu et al., "Enhanced photocatalysis by au nanoparticle loading on $\mathrm{TiO}_{2}$ single-crystal (001) and (110) facets," Journal of Physical Chemistry Letters, vol. 4, no. 22, pp. 3910-3917, 2013.

[78] S. Arrii, F. Morfin, A. J. Renouprez, and J. L. Rousset, "Oxidation of $\mathrm{CO}$ on gold supported catalysts prepared by laser vaporization: direct evidence of support contribution," Journal of the American Chemical Society, vol. 126, no. 4, pp. 1199-1205, 2004.

[79] P. Claus, A. Brückner, C. Mohr, and H. Hofmeister, "Supported gold nanoparticles from quantum dot to mesoscopic size scale: effect of electronic and structural properties on catalytic hydrogenation of conjugated functional groups," Journal of the American Chemical Society, vol. 122, no. 46, pp. 11430-11439, 2000.

[80] H. Masatake, "Catalysis of gold nanoparticles deposited on metal oxides," CATTECH, vol. 6, no. 3, pp. 102-115, 2002.

[81] M. Haruta, "Gold as a novel catalyst in the 21st century: preparation, working mechanism and applications," Gold Bulletin, vol. 37, no. 1-2, pp. 27-36, 2004.

[82] V. Subramanian, E. E. Wolf, and P. V. Kamat, "Catalysis with $\mathrm{TiO}_{2} /$ Gold Nanocomposites. Effect of Metal Particle Size on the 
Fermi Level Equilibration," Journal of the American Chemical Society, vol. 126, no. 15, pp. 4943-4950, 2004.

[83] R. Zanella, S. Giorgio, C. R. Henry, and C. Louis, "Alternative methods for the preparation of gold nanoparticles supported on $\mathrm{TiO}_{2}$," Journal of Physical Chemistry B, vol. 106, no. 31, pp. 76347642, 2002.

[84] A. Visikovskiy, K. Mitsuhara, and Y. Kido, "Role of gold nanoclusters supported on $\mathrm{TiO}_{2}(110)$ model catalyst in $\mathrm{CO}$ oxidation reaction," Journal of Vacuum Science and Technology A Vacuum, Surfaces and Films, vol. 31, no. 6, Article ID 061404, 2013.

[85] M. Boronat, P. Concepción, A. Corma, S. González, F. Illas, and P. Serna, "A molecular mechanism for the chemoselective hydrogenation of substituted nitroaromatics with nanoparticles of gold on $\mathrm{TiO}_{2}$ catalysts: a cooperative effect between gold and the support," Journal of the American Chemical Society, vol. 129, no. 51, pp. 16230-16237, 2007.

[86] J. H. Li, M. J. Feng, and M. L. Jia, "The performance of au nanoparticle supported on mesoporous $\mathrm{TiO}_{2}$ for lowtemperature CO Oxidation," Advanced Materials Research, vol. 726-731, pp. 720-724, 2013.

[87] A. Vittadini and A. Selloni, "Small gold clusters on stoichiometric and defected $\mathrm{TiO}_{2}$ anatase (101) and their interaction with CO: a density functional study," The Journal of Chemical Physics, vol. 117, no. 1, pp. 353-360, 2002.

[88] Z. Zhong, J. Lin, S.-P. Teh, J. Teo, and F. M. Dautzenberg, "A rapid and efficient method to deposit gold particles on catalyst supports and its application for CO oxidation at low temperatures," Advanced Functional Materials, vol. 17, no. 8, pp. 1402-1408, 2007.

[89] S. Yu, Y. Ma, Y. Zhi, H. Jing, and H. Q. Su, "Synthesis of cobaltbased catalyst supported on $\mathrm{TiO}_{2}$ nanotubes and its fischertropsch reaction," Integrated Ferroelectrics, vol. 147, no. 1, pp. 5966, 2013.

[90] F. Lakadamyali, A. Reynal, M. Kato, J. R. Durrant, and E. Reisner, "Electron transfer in dye-sensitised semiconductors modified with molecular cobalt catalysts: photoreduction of aqueous protons," Chemistry-A European Journal, vol. 18, no. 48, pp. 15464-15475, 2012.

[91] Y. C. Lu, M. S. Chen, and Y. W. Chen, "Hydrogen generation by sodium borohydride hydrolysis on nanosized $\mathrm{CoB}$ catalysts supported on $\mathrm{TiO}_{2}, \mathrm{Al}_{2} \mathrm{O}_{3}$ and $\mathrm{CeO}_{2}$," International Journal of Hydrogen Energy, vol. 37, no. 5, pp. 4254-4258, 2012.

[92] P.-O. Larsson, A. Andersson, L. R. Wallenberg, and B. Svensson, "Combustion of $\mathrm{CO}$ and toluene; characterisation of copper oxide supported on titania and activity comparisons with supported cobalt, iron, and manganese oxide," Journal of Catalysis, vol. 163, no. 2, pp. 279-293, 1996.

[93] K. Takanabe, K. Nagaoka, K. Nariai, and K.-I. Aika, “Titaniasupported cobalt and nickel bimetallic catalysts for carbon dioxide reforming of methane," Journal of Catalysis, vol. 232, no. 2, pp. 268-275, 2005.

[94] F. Morales, F. M. F. De Groot, P. Glatzel et al., "In situ Xray absorption of $\mathrm{Co} / \mathrm{Mn} / \mathrm{TiO}_{2}$ catalysts for fischer-tropsch synthesis," Journal of Physical Chemistry B, vol. 108, no. 41, pp. 16201-16207, 2004.

[95] F. Morales, E. de Smit, F. M. F. de Groot, T. Visser, and B. M. Weckhuysen, "Effects of manganese oxide promoter on the $\mathrm{CO}$ and $\mathrm{H} 2$ adsorption properties of titania-supported cobalt Fischer-Tropsch catalysts," Journal of Catalysis, vol. 246, no. 1, pp. 91-99, 2007.
[96] T. E. Feltes, L. Espinosa-Alonso, E. D. Smit et al., "Selective adsorption of manganese onto cobalt for optimized $\mathrm{Mn} / \mathrm{Co} / \mathrm{TiO}_{2}$ Fischer-Tropsch catalysts," Journal of Catalysis, vol. 270, no. 1, pp. 95-102, 2010.

[97] M. C. Aguirre, G. Santori, O. Ferretti, J. L. G. Fierro, and P. Reyes, "Morphological and structural features of $\mathrm{Co} / \mathrm{TiO}_{2}$ catalysts prepared by different methods and their performance in the liquid phase hydrogenation of unsaturated aldehyde," Journal of the Chilean Chemical Society, vol. 51, no. 1, pp. 1-10, 2006.

[98] M. Rakap, E. E. Kalu, and S. Özkar, "Hydrogen generation from the hydrolysis of ammonia borane using cobalt-nickelphosphorus (Co-Ni-P) catalyst supported on $\mathrm{Pd}$-activated $\mathrm{TiO}_{2}$ by electroless deposition," International Journal of Hydrogen Energy, vol. 36, no. 1, pp. 254-261, 2011.

[99] Y. Zhang, K. Liew, J. Li, and X. Zhan, "Fischer-tropsch synthesis on lanthanum promoted $\mathrm{Co} / \mathrm{TiO}_{2}$ catalysts," Catalysis Letters, vol. 139, no. 1-2, pp. 1-6, 2010.

[100] X. Chen, J. Zhang, Y. Huang, Z. Tong, and M. Huang, "Catalytic reduction of nitric oxide with carbon monoxide on coppercobalt oxides supported on nano-titanium dioxide," Journal of Environmental Sciences, vol. 21, no. 9, pp. 1296-1301, 2009.

[101] V. M. Shinde and G. Madras, "CO methanation toward the production of synthetic natural gas over highly active $\mathrm{Ni} / \mathrm{TiO}_{2}$ catalyst," AIChE Journal, vol. 60, no. 3, pp. 1027-1035, 2014.

[102] K. Ullah, S. Ye, S. Sarkar, L. Zhu, Z.-D. Meng, and W.-C. Oh, "Photocatalytic degradation of methylene blue by NiS2graphene supported $\mathrm{TiO}_{2}$ catalyst composites," Asian Journal of Chemistry, vol. 26, no. 1, pp. 145-150, 2014.

[103] H. Song, M. Dai, X. Wan, X. Xu, C. Zhang, and H. Wang, "Synthesis of a $\mathrm{Ni}_{2} \mathrm{P}$ catalyst supported on anatase- $\mathrm{TiO}_{2}$ whiskers with high hydrodesulfurization activity, based on triphenylphosphine," Catalysis Communications, vol. 43, pp. 151-154, 2014.

[104] W. Huo, C. Zhang, H. Yuan et al., "Vapor-phase selective hydrogenation of maleic anhydride to succinic anhydride over $\mathrm{Ni} / \mathrm{TiO}_{2}$ catalysts," Journal of Industrial and Engineering Chemistry, 2014.

[105] W. Kong, X.-H. Zhang, Q. Zhang, T.-J. Wang, L.-L. Ma, and G.-Y. Chen, "Hydrodeoxygenation of guaiacol over nickelbased catalyst supported on mixed oxides," Chemical Journal of Chinese Universities, vol. 34, no. 12, pp. 2806-2813, 2013.

[106] P. Tiwari and S. Basu, "Ni infiltrated YSZ anode stabilization by inducing strong metal support interaction between nickel and titania in solid oxide fuel cell under accelerated testing," International Journal of Hydrogen Energy, vol. 38, no. 22, pp. 9494-9499, 2013.

[107] J. Yan and $\mathrm{H}$. Wang, "Preparation and performance of $\mathrm{Ni} 2 \mathrm{P} / \mathrm{TiO}_{2}-\mathrm{Al}_{2} \mathrm{O}_{3}$ for hydrodenitrogenation," Advanced Materials Research, vol. 634-638, no. 1, pp. 575-580, 2013.

[108] W. E. Kaden, W. A. Kunkel, F. S. Roberts, M. Kane, and S. L. Anderson, "Thermal and adsorbate effects on the activity and morphology of size-selected $\mathrm{Pdn} / \mathrm{TiO}_{2}$ model catalysts," Surface Science, vol. 621, pp. 40-50, 2014.

[109] A. A. Shutilov, G. A. Zenkovets, I. Y. Pakharukov, and I. P. Prosvirin, "Influence of $\mathrm{CeO}_{2}$ addition on the physicochemical and catalytic properties of $\mathrm{Pd} / \mathrm{TiO}_{2}$ catalysts in CO oxidation," Kinetics and Catalysis, vol. 55, no. 1, pp. 111-116, 2014.

[110] K. Kočí, L. Matějová, M. Reli et al., "Sol-gel derived Pd supported $\mathrm{TiO}_{2}-\mathrm{ZrO}_{2}$ and $\mathrm{TiO}_{2}$ photocatalysts; their examination in photocatalytic reduction of carbon dioxide," Catalysis Today, vol. 230, pp. 20-26, 2014. 
[111] K. Cheng, F. Yang, D. Zhang, J. Yin, D. Cao, and G. Wang, "Pd

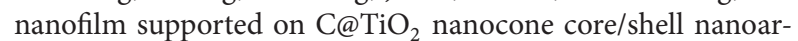
rays: a facile preparation of high performance electrocatalyst for $\mathrm{H}_{2} \mathrm{O}_{2}$ electroreduction in acid medium," Electrochimica Acta, vol. 105, pp. 115-120, 2013.

[112] L. Shahreen, G. G. Chase, A. J. Turinske, S. A. Nelson, and N. Stojilovic, "NO decomposition by $\mathrm{CO}$ over Pd catalyst supported on $\mathrm{TiO}_{2}$ nanofibers," Chemical Engineering Journal, vol. 225, no. 1, pp. 340-349, 2013.

[113] S. Putdee, O. Mekasuwandumrong, A. Soottitantawat, and J. Panpranot, "Characteristics and catalytic behavior of Pd catalysts supported on nanostructure titanate in liquid-phase hydrogenation," Journal of Nanoscience and Nanotechnology, vol. 13, no. 4, pp. 3062-3067, 2013.

[114] R. Chen, Y. Jiang, W. Xing, and W. Jin, "Fabrication and catalytic properties of palladium nanoparticles deposited on a silanized asymmetric ceramic support," Industrial and Engineering Chemistry Research, vol. 50, no. 8, pp. 4405-4411, 2011.

[115] J. Zhu, Y. Jia, M. Li, M. Lu, and J. Zhu, "Carbon nanofibers grown on anatase washcoated cordierite monolith and its supported palladium catalyst for cinnamaldehyde hydrogenation," Industrial and Engineering Chemistry Research, vol. 52, no. 3, pp. 1224-1233, 2013.

[116] H.-S. Sheu, J.-F. Lee, S.-G. Shyu, W.-W. Chou, and J.-R. Chang, "Sulfur resistance enhancement by grafted $\mathrm{TiO}_{2}$ in $\mathrm{SiO}_{2}$ supported Pd catalysts: role of grafted $\mathrm{TiO}_{2}$ and genesis of $\mathrm{Pd}$ clusters," Journal of Catalysis, vol. 266, no. 1, pp. 15-25, 2009.

[117] S. Gatla, N. Madaan, J. Radnik et al., "Rutile-A superior support for highly selective and stable Pd-based catalysts in the gas-phase acetoxylation of toluene," Journal of Catalysis, vol. 297, pp. 256-263, 2013.

[118] S. Maheswari, P. Sridhar, and S. Pitchumani, " $\mathrm{Pd}-\mathrm{TiO}_{2} / \mathrm{C}$ as a methanol tolerant catalyst for oxygen reduction reaction in alkaline medium," Electrochemistry Communications, vol. 26, no. 1, pp. 97-100, 2013.

[119] G. Kennedy, L. R. Baker, and G. A. Somorjai, "Selective amplification of $34 ; \mathrm{O}$ bond hydrogenation on $\mathrm{Pt} / \mathrm{TiO}_{2}$ : catalytic reaction and sum-frequency generation vibrational spectroscopy studies of crotonaldehyde hydrogenation," Angewandte Chemie, vol. 53, no. 13, pp. 3405-3408, 2014.

[120] M. H. Brijaldo, F. B. Passos, H. A. Rojas, and P. Reyes, "Hydrogenation of $\mathrm{m}$-dinitrobenzene over $\mathrm{Pt}$ supported catalysts on $\mathrm{TiO}_{2}-\mathrm{Al}_{2} \mathrm{O}_{3}$ binary oxides," Catalysis Letters, vol. 144, no. 5, pp. 860-863, 2014.

[121] Y. P. G. Chua, G. T. K. K. Gunasooriya, M. Saeys, and E. G. Seebauer, "Controlling the $\mathrm{CO}$ oxidation rate over $\mathrm{Pt} / \mathrm{TiO}_{2}$ catalysts by defect engineering of the $\mathrm{TiO}_{2}$ support," Journal of Catalysis, vol. 311, pp. 306-313, 2014.

[122] G. P. López, R. R. López, and T. Viveros, “Dehydrocyclization of $\mathrm{n}$-heptane over Pt catalysts supported on Al- and Si-promoted TiO ${ }_{2}$," Catalysis Today, vol. 220-222, pp. 61-65, 2014.

[123] B. Ruiz-Camacho, H. H. R. Santoyo, J. M. Medina-Flores, and O. Álvarez-Martínez, "Platinum deposited on $\mathrm{TiO}_{2}-\mathrm{C}$ and $\mathrm{SnO}_{2}$ $\mathrm{C}$ composites for methanol oxidation and oxygen reduction," Electrochimica Acta, vol. 120, pp. 344-349, 2014.

[124] A.-R. Rautio, P. Mäki-Arvela, A. Aho, K. Eränen, and K. Kordas, "Chemoselective hydrogenation of citral by Pt and PtSn catalysts supported on $\mathrm{TiO}_{2}$ nanoparticles and nanowires," Catalysis Today, 2014.

[125] T.-Y. Chang, Y. Tanaka, R. Ishikawa et al., "Direct imaging of pt single atoms adsorbed on $\mathrm{TiO}_{2}$ (110) surfaces," Nano Letters, vol. 14, no. 1, pp. 134-138, 2014.
[126] Q. Du, J. Wu, and H. Yang, "PtNb-TiO 2 catalyst membranes fabricated by electrospinning and atomic layer deposition," ACS Catalysis, vol. 4, no. 1, pp. 144-151, 2014.

[127] S. Gan, Y. Liang, D. R. Baer, M. R. Sievers, G. S. Herman, and C. H. F. Peden, "Effect of platinum nanocluster size and titania surface structure upon CO surface chemistry on platinumsupported $\mathrm{TiO}_{2}$ (110)," Journal of Physical Chemistry B, vol. 105, no. 12, pp. 2412-2416, 2001.

[128] B. Sun, A. V. Vorontsov, and P. G. Smirniotis, "Role of platinum deposited on $\mathrm{TiO}_{2}$ in phenol photocatalytic oxidation," Langmuir, vol. 19, no. 8, pp. 3151-3156, 2003.

[129] J.-M. Herrmann, J. Disdier, and P. Pichat, "Photoassisted platinum deposition on $\mathrm{TiO}_{2}$ powder using various platinum complexes," The Journal of Physical Chemistry, vol. 90, no. 22, pp. 6028-6034, 1986.

[130] J. Yu, L. Qi, and M. Jaroniec, "Hydrogen production by photocatalytic water splitting over $\mathrm{Pt} / \mathrm{TiO}_{2}$ nanosheets with exposed (001) facets," Journal of Physical Chemistry C, vol. 114, no. 30, pp. 13118-13125, 2010.

[131] S. C. Colindres, J. R. V. García, J. A. T. Antonio, and C. A. Chavez, "Preparation of platinum-iridium nanoparticles on titania nanotubes by MOCVD and their catalytic evaluation," Journal of Alloys and Compounds, vol. 483, no. 1-2, pp. 406-409, 2009.

[132] H. Schulz, L. Mädler, R. Strobel, R. Jossen, S. E. Pratsinis, and T. Johannessen, "Independent control of metal cluster and ceramic particle characteristics during one-step synthesis of $\mathrm{Pt} / \mathrm{TiO}_{2}$," Journal of Materials Research, vol. 20, no. 9, pp. 2568-2577, 2005.

[133] S. Shironita, M. Goto, T. Kamegawa, K. Mori, and H. Yamashita, "Preparation of highly active platinum nanoparticles on ZSM5 zeolite including cerium and titanium dioxides as photoassisted deposition sites," Catalysis Today, vol. 153, no. 3-4, pp. 189-192, 2010.

[134] A. Linsebigler, C. Rusu, and J. T. Yates Jr., "Absence of platinum enhancement of a photoreaction on $\mathrm{TiO}_{2}-\mathrm{CO}$ photooxidation on $\mathrm{Pt} / \mathrm{TiO}_{2}$ (110)," Journal of the American Chemical Society, vol. 118, no. 22, pp. 5284-5289, 1996.

[135] K. C. Petallidou, K. Polychronopoulou, S. Boghosian, S. GarciaRodriguez, and A. M. Efstathiou, "Water-gas shift reaction on $\mathrm{Pt} / \mathrm{Ce}_{1-x} \mathrm{Ti}_{x} \mathrm{O}_{2-\delta}$ : the effect of Ce/Ti ratio," Journal of Physical Chemistry C, vol. 117, no. 48, pp. 25467-25477, 2013.

[136] Y. Chen, D. Li, X. Wang, L. Wu, and X. Fu, "Promoting effects of $\mathrm{H} 2$ on photooxidation of volatile organic pollutants over $\mathrm{Pt} / \mathrm{TiO}_{2}$," New Journal of Chemistry, vol. 29, no. 12, pp. 1514-1519, 2005.

[137] S. C. Ammal and A. Heyden, "Origin of the unique activity of $\mathrm{Pt} / \mathrm{TiO}_{2}$ catalysts for the water-gas shift reaction," Journal of Catalysis, vol. 306, pp. 78-90, 2013.

[138] H. Hua, C. Hu, Z. Zha, H. Liu, X. Xie, and Y. Xi, "Pt nanoparticles supported on submicrometer-sized $\mathrm{TiO}_{2}$ spheres for effective methanol and ethanol oxidation," Electrochimica Acta, vol. 105, pp. 130-136, 2013.

[139] C. Zhang, H. Yu, Y. Li et al., "Simple synthesis of $\mathrm{Pt} / \mathrm{TiO}_{2}$ nanotube arrays with high activity and stability," Journal of Electroanalytical Chemistry, vol. 701, pp. 14-19, 2013.

[140] X. Li, W. Zheng, H. Pan, Y. Yu, L. Chen, and P. Wu, "Pt nanoparticles supported on highly dispersed $\mathrm{TiO}_{2}$ coated on SBA-15 as an efficient and recyclable catalyst for liquid-phase hydrogenation," Journal of Catalysis, vol. 300, pp. 9-19, 2013.

[141] H. An, P. Hu, X. Hu et al., "Characterization of Pt catalysts supported by three forms of $\mathrm{TiO}_{2}$ and their catalytic activities for 
hydrogenation," Reaction Kinetics, Mechanisms and Catalysis, vol. 108, no. 1, pp. 117-126, 2013.

[142] M. N. Shaddad, A. M. Al-Mayouf, M. A. Ghanem, M. S. AlHoshan, J. P. Singh, and A. A. Al-Suhybani, "Chemical deposition and electrocatalytic activity of platinum nanoparticles supported on $\mathrm{TiO}_{2}$ nanotubes," International Journal of Electrochemical Science, vol. 8, no. 2, pp. 2468-2478, 2013.

[143] Y. L. Shen, S. Y. Chen, J. M. Song, and I. G. Chen, "Ultralong pt nanolawns supported on $\mathrm{TiO}_{2}$-coated carbon fibers as 3D hybrid catalyst for methanol oxidation," Nanoscale Research Letters, vol. 7, pp. 1-8, 2012.

[144] X.-Y. Hao, Y.-Q. Zhang, J.-W. Wang, W. Zhou, C. Zhang, and S. Liu, "A novel approach to prepare MCM-41 supported $\mathrm{CuO}$ catalyst with high metal loading and dispersion," Microporous and Mesoporous Materials, vol. 88, no. 1-3, pp. 38-47, 2006.

[145] Y. Xue, G. Lu, Y. Guo, Y. Guo, Y. Wang, and Z. Zhang, "Effect of pretreatment method of activated carbon on the catalytic reduction of NO by carbon over CuO," Applied Catalysis B: Environmental, vol. 79, no. 3, pp. 262-269, 2008.

[146] F. Severino, J. L. Brito, J. Laine, J. L. G. Fierro, and A. López Agudo, "Nature of copper active sites in the carbon monoxide oxidation on $\mathrm{CuAl}_{2} \mathrm{O}_{4}$ and $\mathrm{CuCr}_{2} \mathrm{O}_{4}$ spinel type catalysts," Journal of Catalysis, vol. 177, no. 1, pp. 82-95, 1998.

[147] N. Pasha, N. Lingaiah, P. S. S. Reddy, and P. S. Prasad, "Direct decomposition of $\mathrm{N}_{2} \mathrm{O}$ over cesium-doped $\mathrm{CuO}$ catalysts," Catalysis Letters, vol. 127, no. 1-2, pp. 101-106, 2009.

[148] A. Chowdhuri, S. K. Singh, K. Sreenivas, and V. Gupta, "Contribution of adsorbed oxygen and interfacial space charge for enhanced response of $\mathrm{SnO}_{2}$ sensors having $\mathrm{CuO}$ catalyst for $\mathrm{H}_{2} \mathrm{~S}$ gas," Sensors and Actuators B: Chemical, vol. 145, no. 1, pp. 155$166,2010$.

[149] A. Martínez-Arias, M. Fernández-García, O. Gálvez et al., "Comparative study on redox properties and catalytic behavior for $\mathrm{CO}$ oxidation of $\mathrm{CuO} / \mathrm{CeO}_{2}$ and $\mathrm{CuO} / \mathrm{ZrCeO}_{4}$ catalysts," Journal of Catalysis, vol. 195, no. 1, pp. 207-216, 2000.

[150] X. Yao, L. Zhang, L. Li et al., "Investigation of the structure, acidity, and catalytic performance of $\mathrm{CuO} / \mathrm{Ti}_{0.95} \mathrm{Ce}_{0.05} \mathrm{O}_{2}$ catalyst for the selective catalytic reduction of $\mathrm{NO}$ by $\mathrm{NH}_{3}$ at low temperature," Applied Catalysis B: Environmental, vol. 150-151, pp. 315-329, 2014.

[151] C. G. Maciel, T. D. F. Silva, E. M. Assaf, and J. M. Assaf, "Hydrogen production and purification from the water-gas shift reaction on $\mathrm{CuO} / \mathrm{CeO}_{2}-\mathrm{TiO}_{2}$ catalysts," Applied Energy, vol. 112, pp. 52-59, 2013.

[152] Z. Rui, Y. Huang, Y. Zheng, H. Ji, and X. Yu, "Effect of titania polymorph on the properties of $\mathrm{CuO} / \mathrm{TiO}_{2}$ catalysts for trace methane combustion," Journal of Molecular Catalysis A: Chemical, vol. 372, pp. 128-136, 2013.

[153] H. Zhu, L. Dong, and Y. Chen, "Effect of titania structure on the properties of its supported copper oxide catalysts," Journal of Colloid and Interface Science, vol. 357, no. 2, pp. 497-503, 2011.

[154] D. Dean, B. Davis, and P. G. Jessop, "The effect of temperature, catalyst and sterics on the rate of N-heterocycle dehydrogenation for hydrogen storage," New Journal of Chemistry, vol. 35, no. 2, pp. 417-422, 2011.

[155] Y. Gu, Y. Yang, Y. Qiu, K. Sun, and X. Xu, "Combustion of dichloromethane using copper-manganese oxides supported on zirconium modified titanium-aluminum catalysts," Catalysis Communications, vol. 12, no. 4, pp. 277-281, 2010.

[156] V. Gombac, L. Sordelli, T. Montini et al., "CuO $\mathrm{Cu}_{x}-\mathrm{TiO}_{2}$ Photocatalysts for $\mathrm{H} 2$ production from ethanol and glycerol solutions,"
Journal of Physical Chemistry A, vol. 114, no. 11, pp. 3916-3925, 2010.

[157] J. Ren, S. Liu, Z. Li, X. Lu, and K. Xie, "Oxidative carbonylation of methanol to dimethyl carbonate over $\mathrm{CuCl} / \mathrm{SiO}_{2}-\mathrm{TiO}_{2}$ catalysts prepared by microwave heating: The effect of support composition," Applied Catalysis A General, vol. 366, no. 1, pp. 93-101, 2009.

[158] S. Pradhan, A. S. Reddy, R. N. Devi, and S. Chilukuri, "Copperbased catalysts for water gas shift reaction: influence of support on their catalytic activity," Catalysis Today, vol. 141, no. 1-2, pp. 72-76, 2009.

[159] J.-N. Nian, S.-A. Chen, C.-C. Tsai, and H. Teng, "Structural feature and catalytic performance of $\mathrm{Cu}$ species distributed over $\mathrm{TiO}_{2}$ nanotubes," The Journal of Physical Chemistry B, vol. 110, no. 51, pp. 25817-25824, 2006.

[160] J. Huang, S. Wang, Y. Zhao et al., "Synthesis and characterization of $\mathrm{CuO} / \mathrm{TiO}_{2}$ catalysts for low-temperature $\mathrm{CO}$ oxidation," Catalysis Communications, vol. 7, no. 12, pp. 1029-1034, 2006.

[161] A. A. Altynnikov, L. T. Tsikoza, and V. F. Anufrienko, "Ordering of $\mathrm{Cu}(\mathrm{II})$ ions in supported copper-titanium oxide catalysts," Journal of Structural Chemistry, vol. 47, no. 6, pp. 1161-1169, 2006.

[162] K. V. R. Chary, G. V. Sagar, D. Naresh, K. K. Seela, and B. Sridhar, "Characterization and reactivity of copper oxide catalysts supported on $\mathrm{TiO}_{2}-\mathrm{ZrO}_{2}$," Journal of Physical Chemistry B, vol. 109, no. 19, pp. 9437-9444, 2005.

[163] G. Centi, "Nature of active layer in vanadium oxide supported on titanium oxide and control of its reactivity in the selective oxidation and ammoxidation of alkylaromatics," Applied Catalysis A: General, vol. 147, no. 2, pp. 267-298, 1996.

[164] A. Miyamoto, Y. Yamazaki, M. Inomata, and Y. Murakami, "Determination of the number of vanadium=oxygen species on the surface of vanadium oxide catalysts. 1. Unsupported vanadium pentoxide and vanadium pentoxide /titanium dioxide treated with an ammoniacal solution," Journal of Physical Chemistry, vol. 85, no. 16, pp. 2366-2372, 1981.

[165] W. E. Slink and P. B. DeGroot, "Vanadium-titanium oxide catalysts for oxidation of butene to acetic acid," Journal of Catalysis, vol. 68, no. 2, pp. 423-432, 1981.

[166] A. H. S. Kootenaei, J. Towfighi, A. Khodadadi, and Y. Mortazavi, "Stability and catalytic performance of vanadia supported on nanostructured titania catalyst in oxidative dehydrogenation of propane," Applied Surface Science, vol. 298, pp. 26-35, 2014.

[167] Y. Pan, W. Zhao, Q. Zhong, W. Cai, and H. Li, "Promotional effect of Si-doped $\mathrm{V}_{2} \mathrm{O}_{5} / \mathrm{TiO}_{2}$ for selective catalytic reduction of NO $x$ by NH3," Journal of Environmental Sciences, vol. 25, no. 8, pp. 1703-1711, 2013 (Chinese).

[168] S. Feyel, D. Schröder, and H. Schwarz, "Gas-phase oxidation of isomeric butenes and small alkanes by vanadium-oxide andhydroxide cluster cations," Journal of Physical Chemistry A, vol. 110, no. 8, pp. 2647-2654, 2006.

[169] M. Setnička, P. Čičmanec, R. Bulánek, A. Zukal, and J. Pastva, "Hexagonal mesoporous titanosilicates as support for vanadium oxide-promising catalysts for the oxidative dehydrogenation of n-butane," Catalysis Today, vol. 204, pp. 132-139, 2013.

[170] K. N. Rao, P. Venkataswamy, P. Bharali, H. P. Ha, and B. M. Reddy, "Monolayer $\mathrm{V}_{2} \mathrm{O}_{5} / \mathrm{TiO}_{2}-\mathrm{ZrO}_{2}$ catalysts for selective oxidation of o-xylene: preparation and characterization," Research on Chemical Intermediates, vol. 38, no. 3, pp. 733-744, 2012.

[171] J. E. Herrera, T. T. Isimjan, I. Abdullahi, A. Ray, and S. Rohani, "A novel nanoengineered VO x catalyst supported on highly 
ordered $\mathrm{TiO}_{2}$ nanotube arrays for partial oxidation reactions," Applied Catalysis A General, vol. 417-418, pp. 13-18, 2012.

[172] S. Chin, J. Jurng, J.-H. Lee, and S.-J. Moon, "Catalytic conversion of 1,2-dichlorobenzene using $\mathrm{V}_{2} \mathrm{O}_{5} / \mathrm{TiO}_{2}$ catalysts by a thermal decomposition process," Chemosphere, vol. 75, no. 9, pp. 12061209, 2009.

[173] M. Inomata, A. Miyamoto, and Y. Murakami, "Determination of the number of vanadium $=$ oxygen species on the surface of vanadium oxide catalysts. 2. Vanadium pentoxide /titanium dioxide catalysts," Journal of Physical Chemistry, vol. 85, no. 16, pp. 2372-2377, 1981.

[174] S. Chin, E. Park, M. Kim, G. N. Bae, and J. Jurng, "Effect of the support material $\left(\mathrm{TiO}_{2}\right)$ synthesis conditions in chemical vapor condensation on the catalytic oxidation for 1,2-dichlorobenzene over $\mathrm{V}_{2} \mathrm{O}_{5} / \mathrm{TiO}_{2}$," Powder Technology, vol. 217, pp. 388-393, 2012.

[175] F. Zhang, F. Chen, Q. Xiao, Y. Zhong, and W. Zhu, "Ammoxidation of 3-picoline over $\mathrm{V}_{2} \mathrm{O}_{5} / \mathrm{TiO}_{2}$ catalysts: effects of $\mathrm{TiO}_{2}$ supports on the catalytic performance," Advanced Materials Research, vol. 396-398, pp. 791-797, 2012.

[176] T. Fievez, F. de Proft, P. Geerlings, B. M. Weckhuysen, and R. W. A. Havenith, "Conceptual chemistry approach towards the support effect in supported vanadium oxides: valence bond calculations on the ionicity of vanadium catalysts," Catalysis Today, vol. 177, no. 1, pp. 3-11, 2011.

[177] A. Löfberg, T. Giornelli, S. Paul, and E. Bordes-Richard, "Catalytic coatings for structured supports and reactors: $\mathrm{VO}_{x} / \mathrm{TiO}_{2}$ catalyst coated on stainless steel in the oxidative dehydrogenation of propane," Applied Catalysis A: General, vol. 391, no. 1-2, pp. 43-51, 2011.

[178] G. Lü, C.-L. Song, F. Bin, Q.-M. Zhang, and Y.-Q. Pei, "Physicochemical properties and catalytic activity of vanadium contained SCR catalysts with different synthetic methods," Journal of Engineering Thermophysics, vol. 30, no. 12, pp. 21572160, 2009.

[179] Y.-T. Li, Q. Zhong, and W.-H. Ma, "Preparation and activity of F-doped VOx/TiOy low temperature SCR catalysts," Dongli Gongcheng/Power Engineering, vol. 29, no. 9, pp. 854-858, 2009.

[180] S. H. Choi, S. P. Cho, J. Y. Lee, S. H. Hong, S. C. Hong, and S.-I. Hong, "The influence of non-stoichiometric species of $\mathrm{V} / \mathrm{TiO}_{2}$ catalysts on selective catalytic reduction at low temperature," Journal of Molecular Catalysis A: Chemical, vol. 304, no. 1-2, pp. 166-173, 2009.

[181] T. Carlson and G. L. Griffin, "Photooxidation of methanol using $\mathrm{V}_{2} \mathrm{O}_{5} / \mathrm{TiO}_{2}$ and $\mathrm{MoO}_{3} / \mathrm{TiO}_{2}$ surface oxide monolayer catalysts," Journal of Physical Chemistry, vol. 90, no. 22, pp. 5896-5900, 1986.

[182] O. Susumu, K. Masanori, Y. Jiro, K. Koji, and T. Kozo, "Effect of sulfate ion on the catalytic activity of molybdenum oxidetitanium dioxide $\left(\mathrm{MoO}_{x}-\mathrm{TiO}_{2}\right)$ for the reduction of nitric oxide with ammonia," Industry Engineering Chemical Production Research Division, vol. 20, no. 2, pp. 301-304, 1981.

[183] K. Ramesh, L. Chen, F. Chen, Y. Liu, Z. Wang, and Y.-F. Han, "Re-investigating the $\mathrm{CO}$ oxidation mechanism over unsupported $\mathrm{MnO}, \mathrm{Mn}_{2} \mathrm{O}_{3}$ and $\mathrm{MnO}_{2}$ catalysts," Catalysis Today, vol. 131, no. 1, pp. 477-482, 2008.

[184] L. E. Cadus and O. Ferretti, "Characterization of Mo-MnO catalyst for propane oxidative dehydrogenation," Applied Catalysis A: General, vol. 233, no. 1-2, pp. 239-253, 2002.

[185] G. Qi, R. T. Yang, and R. Chang, " $\mathrm{MnO}_{x}-\mathrm{CeO}_{2}$ mixed oxides prepared by co-precipitation for selective catalytic reduction of NO with $\mathrm{NH} 3$ at low temperatures," Applied Catalysis B: Environmental, vol. 51, no. 2, pp. 93-106, 2004.

[186] Z. An, Y. Zhuo, C. Xu, and C. Chen, "Influence of the $\mathrm{TiO}_{2}$ crystalline phase of $\mathrm{MnOx} / \mathrm{TiO}_{2}$ catalysts for $\mathrm{NO}$ oxidation," Chinese Journal of Catalysis, vol. 35, no. 1, pp. 120-126, 2014.

[187] Z. Peng, L. Zhong, H. Li, S. Zhang, and Q. Zhong, "Catalytic performance research of $\mathrm{N}$-doped $\mathrm{MnOx} / \mathrm{TiO}_{2}$ for lowtemperature selective reduction of $\mathrm{NO}$ with $\mathrm{NH}_{3}$," Proceedings of the Chinese Society of Electrical Engineering, vol. 33, no. 35, pp. 58-66, 2013.

[188] A. Aboukaïs, E. Abi-Aad, and B. Taouk, "Supported manganese oxide on $\mathrm{TiO}_{2}$ for total oxidation of toluene and polycyclic aromatic hydrocarbons (PAHs): characterization and catalytic activity," Materials Chemistry and Physics, vol. 142, no. 2-3, pp. 564-571, 2013.

[189] S. Feng, P. Gao, C. Dong, and Q. Lu, “The effect of doping Ce and Fe on the $\mathrm{Mn} / \mathrm{TiO}_{2}$ catalyst for low temperature NO selective catalytic reduction with $\mathrm{NH}_{3}$," Applied Mechanics and Materials, vol. 261-262, pp. 1041-1046, 2013.

[190] Z. Wu, B. Jiang, and Y. Liu, "Effect of transition metals addition on the catalyst of manganese/titania for low-temperature selective catalytic reduction of nitric oxide with ammonia," Applied Catalysis B Environmental, vol. 79, no. 4, pp. 347-355, 2008.

[191] P. G. Smirniotis, P. M. Sreekanth, D. A. Peña, and R. G. Jenkins, "Manganese oxide catalysts supported on $\mathrm{TiO}_{2}, \mathrm{Al} 2 \mathrm{O}_{3}$, and $\mathrm{SiO}_{2}$ : a comparison for low-temperature SCR of NO with $\mathrm{NH}_{3}$," Industrial and Engineering Chemistry Research, vol. 45, no. 19, pp. 6436-6443, 2006.

[192] S. S. Kim and S. C. Hong, "Improving the activity of $\mathrm{Mn} / \mathrm{TiO}_{2}$ catalysts through control of the $\mathrm{pH}$ and valence state of Mn during their preparation," Journal of the Air and Waste Management Association, vol. 62, no. 3, pp. 362-369, 2012.

[193] S. M. Lee, K. H. Park, and S. C. Hong, " $\mathrm{MnOx} / \mathrm{CeO}_{2}-\mathrm{TiO}_{2}$ mixed oxide catalysts for the selective catalytic reduction of $\mathrm{NO}$ with $\mathrm{NH}_{3}$ at low temperature," Chemical Engineering Journal, vol. 195-196, pp. 323-331, 2012.

[194] G. S. Pozan, "Effect of support on the catalytic activity of manganese oxide catalyts for toluene combustion," Journal of Hazardous Materials, vol. 221-222, pp. 124-130, 2012.

[195] X. Li, H.-Y. Liu, Q.-B. Xia, Z.-M. Liu, X. Jiang, and Z. Li, "Preparation of $\mathrm{MnCe}(\mathrm{y}) \mathrm{O}_{x} / \mathrm{TiO}_{2}$ catalysts and their catalytic activity for catalytic combustion of toluene," Journal of Functional Materials, vol. 43, no. 10, pp. 1357-1360, 2012.

[196] D. W. Wu, Q. L. Zhang, T. Lin, M. C. Gong, and Y. Q. Chen, "Effect of $\mathrm{Fe}$ on the selective catalytic reduction of $\mathrm{NO}$ by $\mathrm{NH}_{3}$ at low temperature over $\mathrm{Mn} / \mathrm{CeO}_{2}-\mathrm{TiO}_{2}$ catalyst," Journal of Inorganic Materials, vol. 27, no. 5, pp. 495-500, 2012.

[197] B. Thirupathi and P. G. Smirniotis, "Nickel-doped $\mathrm{Mn} / \mathrm{TiO}_{2}$ as an efficient catalyst for the low-temperature SCR of NO with $\mathrm{NH}_{3}$ : catalytic evaluation and characterizations," Journal of Catalysis, vol. 288, pp. 74-83, 2012.

[198] G. Blondeel, A. Harriman, G. Porter, D. Urwin, and J. Kiwi, "Design, preparation, and characterization of $\mathrm{RuO}_{2} / \mathrm{TiO}_{2}$ colloidal catalytic surfaces active in photooxidation of water," Journal of Physical Chemistry, vol. 87, no. 14, pp. 2629-2636, 1983.

[199] N. Perkas, D. P. Minh, P. Gallezot, A. Gedanken, and M. Besson, "Platinum and ruthenium catalysts on mesoporous titanium and zirconium oxides for the catalytic wet air oxidation of model compounds," Applied Catalysis B: Environmental, vol. 59, no. 1-2, pp. 121-130, 2005. 
[200] K. E. Swider, C. I. Merzbacher, P. L. Hagans, and D. R. Rolison, "Synthesis of ruthenium dioxide-titanium dioxide aerogels: redistribution of electrical properties on the nanoscale," Chemistry of Materials, vol. 9, no. 5, pp. 1248-1255, 1997.

[201] J. Ju, Y. Shi, and D. Wu, “ $\mathrm{TiO}_{2}$ nanotube supported PdNi catalyst for methanol electro-oxidation," Powder Technology, vol. 230, pp. 252-256, 2012.

[202] C. L. Bracey, P. R. Ellis, and G. J. Hutchings, "Application of copper-gold alloys in catalysis: current status and future perspectives," Chemical Society Reviews, vol. 38, no. 8, pp. 22312243, 2009.

[203] S. Ajaikumar, J. Ahlkvist, W. Larsson et al., "Oxidation of $\alpha$ pinene over gold containing bimetallic nanoparticles supported on reducible $\mathrm{TiO}_{2}$ by deposition-precipitation method," Applied Catalysis A: General, vol. 392, no. 1-2, pp. 11-18, 2011.

[204] G. Kazantzis, "Role of cobalt, iron, lead, manganese, mercury, platinum, selenium, and titanium in carcinogenesis," Environmental Health Perspectives, vol. 40, pp. 143-161, 1981.

[205] F. Morales, E. de Smit, F. M. F. de Groot, T. Visser, and B. M. Weckhuysen, "Effects of manganese oxide promoter on the $\mathrm{CO}$ and $\mathrm{H}_{2}$ adsorption properties of titania-supported cobalt Fischer-Tropsch catalysts," Journal of Catalysis, vol. 246, no. 1, pp. 91-99, 2007.

[206] F. Morales, F. M. F. De Groot, O. L. J. Gijzeman, A. Mens, O. Stephan, and B. M. Weckhuysen, "Mn promotion effects in $\mathrm{Co} / \mathrm{TiO}_{2}$ Fischer-Tropsch catalysts as investigated by XPS and STEM-EELS," Journal of Catalysis, vol. 230, no. 2, pp. 301-308, 2005.

[207] P. Weerachawanasak, G. J. Hutchings, J. K. Edwards et al., "Surface functionalized $\mathrm{TiO}_{2}$ supported Pd catalysts for solventfree selective oxidation of benzyl alcohol," Catalysis Today, 2014.

[208] U. Arellano, J. A. Wang, M. T. Timko et al., "Oxidative removal of dibenzothiophene in a biphasic system using sol-gel $\mathrm{FeTiO}_{2}$ catalysts and $\mathrm{H}_{2} \mathrm{O}_{2}$ promoted with acetic acid," Fuel, vol. 126, pp. 16-25, 2014. 

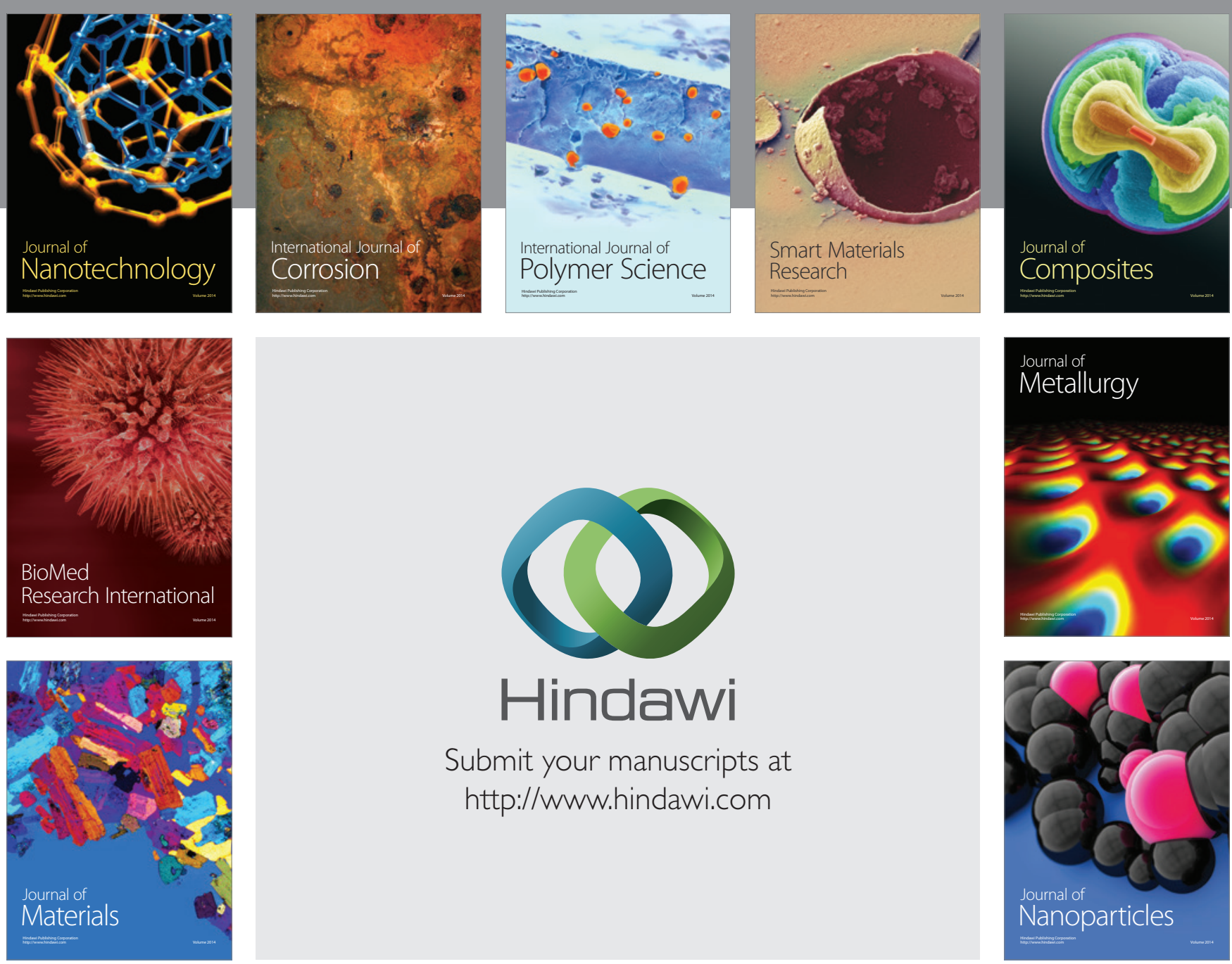

Submit your manuscripts at http://www.hindawi.com
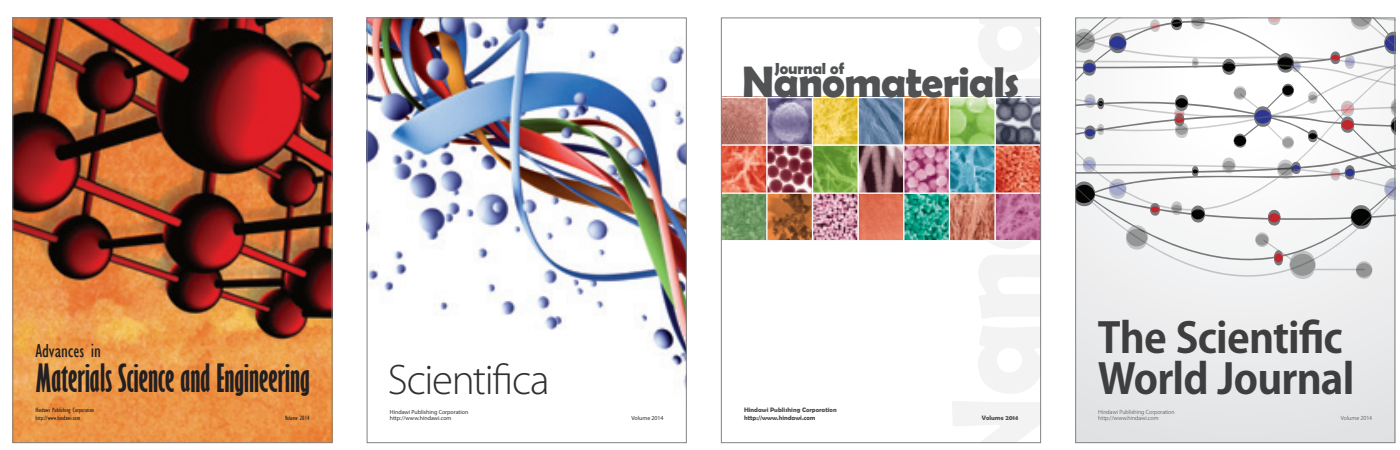

\section{The Scientific World Journal}
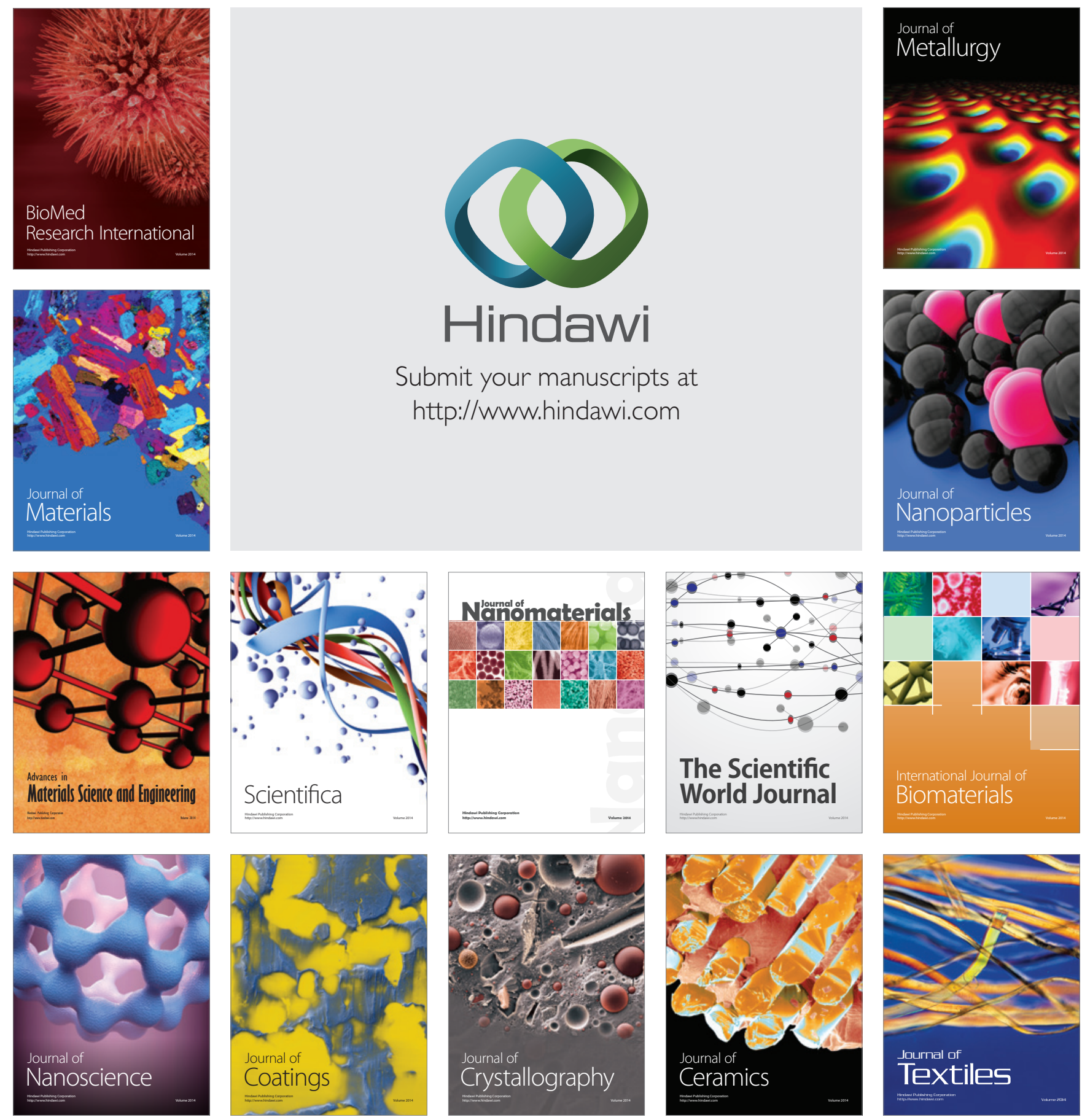